\title{
Intra-destination travel behavior of alpine tourists: a literature review on choice determinants and the survey work
}

\author{
Bartosz Bursa $^{1}$ (D) Markus Mailer ${ }^{1}$ (D) Kay W. Axhausen ${ }^{2}$ (D)
}

Accepted: 17 January 2022 / Published online: 4 February 2022

(c) The Author(s) 2022

\begin{abstract}
In the face of a continuous increase in the number of tourists in the Alps, the associated traffic volumes, and the resulting negative externalities, there is an urgent need to design policies capable of managing tourist traffic efficiently and to invest in transport systems and infrastructure wisely, given the limited financial, spatial and environmental resources. Unfortunately, while there is a considerable research interest in long-distance travel and arrival/departure patterns of tourists, research on tourist mobility during the stay at the destination is almost non-existent. This prevents policy-makers from making informed decisions backed by scientific evidence. The paper presents a data collection study that contributes to filing this gap. This 'data paper' reports on the motivation, design and administration of a bespoke travel-activity survey of tourists at vacation destinations. It informs other researchers about the encountered difficulties and helps them optimize data collection effort in their future studies. Besides the contribution to survey methodology, the paper reports on a rare and policy-relevant dataset, provides descriptive results, and thereby contributes to evidence-based design of transport policies in tourist regions. With this paper, we also want to inspire and invite researchers to conduct further quantitative and modeling work in this under-studied field.
\end{abstract}

Keywords Tourist travel behavior · Intra-destination · Tourist survey $\cdot$ Survey design · Survey work - Data paper

Bartosz Bursa

bartosz.bursa@uibk.ac.at

Markus Mailer

markus.mailer@uibk.ac.at

Kay W. Axhausen

axhausen@ivt.baug.ethz.ch

1 Unit of Intelligent Transport Systems, University of Innsbruck, 6020 Innsbruck, Austria

2 Institute for Transport Planning and Systems (IVT), ETH Zurich, 8093 Zurich, Switzerland 


\section{Introduction and motivation}

Tourism industry accounts for a substantial share of the direct Gross Domestic Product (GDP) in the Alpine areas of Austria, Switzerland, Italy or France. In the Austrian province of Tyrol, for example, it is responsible for 17.5\% of the GDP (Werbung 2019). However, over the past two decades, vacation trends, characteristics and demands of customers who bring in these revenues have changed significantly. While the average length of stay of tourists in Tyrol decreased from 5.1 nights in 2000 to 4.0 nights in 2019 , the number of arrivals increased by almost $60 \%$ from around 8 million to more than 12 million (Statistics Austria 2020). This demonstrates the rising demand for tourist stays in the province of Tyrol (despite no expansion on the supply side, as the number of beds dropped by $7 \%$ between 2000 and 2019), which inevitably leads to an increase in tourism-related travel.

In Austria, nearly $75 \%$ of inbound holiday trips are made by private car (Austrian National Tourist Office 2014). These trips have a substantial influence on traffic congestion on alpine roads and generate pollution in environmentally fragile areas. Car travel, due to its dominant role in Austrian tourism, heavily contributes to the sector's greenhouse gas emissions, both at the level of a single destination (Unger et al. 2016), as well as for the entire country (Gühnemann et al. 2021). Tourists appear to be well aware of their travel carbon footprint, yet are not willing to change their behavior substantially (Mailer et al. 2019). Furthermore, traffic generated by tourists can even disrupt daily activities and travel patterns of local inhabitants, who experience severe difficulties in traveling due to lack of alternative roads in densely built-up and narrow mountain valleys. The problem is recognized and present also in other non-urban destinations, but has so far attracted only limited attention of researchers, who addressed it in qualitative studies (Dickinson and Robbins 2007, 2008). Local authorities still do not have any quantitative evidence at their disposal. In effect, transport policy measures in tourist regions are often shots in the dark, which, despite considerable expenses (e.g. free public transportation for tourists), lack proper evaluation and appraisal.

Compared to what we know about everyday travel behavior from representative household surveys, census studies and extensive scientific literature, our knowledge of transportation behavior during vacations is very limited. While these studies provide information on specific vacation decisions (destination preferences, spending, etc.), they look at the issue from the perspective of the country of origin, for which respondents' behavior during a stay abroad is not relevant. Similarly, data collected by national tourism agencies and international organizations on tourism markets and aggregate statistics on travelers moving between and within countries are not helpful here either. It is, however, rational and legitimate to assume that travel behavior of tourists at the destination is not only different from their everyday behavior at home (Schlemmer et al. 2019), but it is also dissimilar to travel behavior of local residents. Yet, current research in this field is limited and concentrates merely on international tourism demand and the long-distance component of vacation travel (Christensen and Nielsen 2018; Gerike and Schulz 2018; Janzen et al. 2018). There are virtually no quantitative data documenting tourists' travel decisions while at the destination, leaving their travel behavior still largely unexplored.

The fundamental goal of current work is to help fill this research gap by developing a scientifically-grounded approach to collecting data on tourist travel behavior at the destination and by providing tourism practitioners, transport planners and policy-makers with a first-of-its-kind dataset from a survey conducted in the Austrian Alps. 
The paper is comprised of four sections with Sect. Introduction and motivation introducing the topic, describing the motivation and setting the objectives for the research. Section State of research on travel behavior of tourists reviews the literature on data collection methods and travel decisions, with a particular focus on tourists in vacation setting. Section Survey design covers the survey work. First, the conceptual framework of tourist travel at the destination is presented. Next, a detailed description of survey methodology and design is given, followed by response behavior statistics from a survey conducted in the field. Section Descriptive analysis provides a descriptive analysis of the collected data. Section Conclusion synthesizes and discusses the findings, and points out the limitations. We also provide an outlook on future research and suggest prospective study topics that could either extend the approach or resolve some of its limitations.

\section{State of research on travel behavior of tourists}

\section{Definitions}

As noticed by Arce and Pisarski (2009), there are many future challenges in describing tourists' mobility that are caused by i.e. data unavailability, different levels of analysis or inconsistencies in definitions. Therefore, several assumptions were made in the paper to avoid ambiguities. We operate with the definitions of tourism and tourist as proposed by United Nations (2010), so as to avoid confusion with traveler, vacationer or holidaymaker (Terrier 2009). All these terms are used in the paper interchangeably though all meaning a tourist. The main restriction this definition of tourist imposes, is that a person should be out of home (place of residence) for at least one night. It can be either a domestic or an inbound (foreign) visitor. The person must not be specifically on vacation, business purposes or family visits are also allowed. It cannot be however a seasonal worker. Of interest are all trips and activities performed during the stay (leisure and non-leisure).

\section{Data collection methods}

The technological progress in recent years has provided academics with new opportunities for measuring mobility by utilizing passively collected big data. Apart from transport researchers also tourism researchers applied tracking technologies in a number of studies (Shoval et al. 2014; Shoval and Ahas 2016). However, these deal with research questions relevant for tourism marketing or tourism geography, but not with the transportationrelated aspects of tourist travel, such as traffic generated at destinations or transport mode choice.

Mobile positioning data have been widely utilized by tourism researchers in the last decade (Ahas et al. 2008; Zhao et al. 2018). Yet, they proved useful only in applications limited to long-distance travel demand and tourism statistics. In transportation, decisions strongly depend on characteristics of decision-makers (Lu and Pas 1999) and mobile positioning data, for technical and ethical reasons, are lacking this information-only pure location data with time stamps are available. Unfortunately, the density of GSM transceiver stations in mountain regions is typically insufficient for high-resolution analysis at the destination level. In addition, in Alpine regions, cross-border trips are very common, resulting in frequent changes of network provider. Thus, only parts of these trips will appear in the dataset obtained from a national provider. 
GPS tracking can deliver very fine-grained data on tourist mobility allowing analyses of specific activities or monitoring visitors to facilities, parks and venues ( $\mathrm{Li}$ et al. 2019). If complemented with additional questionnaires, GPS tracking can serve as a superior alternative to traditional travel surveys among tourists. Currently, mobile phones appear to be used more often in research than independent GPS trackers, since smartphone apps allow for correcting and annotating trips by the user and answering supplementary questions (Prelipcean et al. 2018). Although the first studies reported on failed attempts of GPS tracking with mobile phones (McKercher and Lau 2009), the success rate has increased over the last few years. So far, the most complete and successful approach that combines an annotated travel diary and GPS tracking in a smartphone app for tourist tracking was developed by Hardy et al. (2017), who distributed 240 smartphones with a preinstalled tracking app among visitors to Tasmania. However, besides high costs of such studies, there are also practical and organizational burdens. Tourists cannot be contacted before arrival to arrange handing over the GPS units. In the case of a smartphone app, a communication channel is necessary to make tourists aware of the app. Furthermore, battery consumption and data roaming in the case of foreign visitors have to be considered. Nonetheless, it is a promising approach and deserves further testing in the field.

Another alternative data source are social media platforms. Recent studies approximated tourist mobility patterns from geo-located Twitter data (Chua et al. 2016; Provenzano et al. 2018), Flickr photos (Önder et al. 2016; Yang et al. 2017) or Foursquare check-ins (Vu et al. 2018). However, in less populated areas, relevant Points-of-Interest are underrepresented and geo-tagged tweets and photos are scarce, making these methods more suitable studying urban tourism (Sobolevsky et al. 2015) or estimating inter-destination tourist flows (Barchiesi et al. 2015). Moreover, even though such data can deliver valuable information on tourist activity for the destination managers (Orsi and Geneletti 2013), they are of little use to transportation planners since it is impossible to fully reconstruct all trips made.

Nevertheless, despite the expansion of big data, traditional surveys appear to be still in use when investigating tourist populations. Big data on their own are not capable of substituting traditional methods as they do not provide sociodemographic information, cannot measure unobserved variables or deliver strong causal evidence (Chen et al. 2016; Mokhtarian 2018). Unfortunately, as opposed to well-established surveys on daily travel behavior (Brög 2009), there is no consensus on the design and methodology of such surveys in the tourism context that could lead to a replicable approach. Also, very few researchers provide details on the survey design and report on the fieldwork when applying travel diaries (Newmark 2014; Thornton et al. 1997; Tschopp et al. 2010). Authors' experiences confirm many weaknesses of diary-based surveys of tourists that are also known from surveys of daily mobility, i.e. high costs, low response rate and high dropout rate. Besides, due to high spatiotemporal dynamics of tourists on site, the sampling frame is unknown and it is difficult to approach a representative sample when surveying outdoors. Surveying visitors at their accommodations allows for more control over sampling (e.g. indirect sampling through hotels), but it requires a close cooperation with the accommodation providers, which is usually impossible without the support of local Destination Marketing Organizations (DMO). Even so, self-administered questionnaires distributed through tourism establishments prove very ineffective. It is therefore postulated that only fully-assisted interviews can guarantee good quality results. Moreover, although travel diary data is detailed enough to model destination and mode choice, it is usually insufficient to investigate route choice. Many of the above issues were discussed by Thornton et al. back in 1997 and are still valid today. 


\section{Destination choice on vacation}

Provided that the decision to travel has been taken, decisions must be made about the nature of the trip. The three fundamental dimensions of travel decision-making are destination choice, transport mode choice and route choice. In the context of holiday travel, Bieger and Laesser (2013) distinguish between inter-destination mobility (long-distance travel from home to a destination) and intra-destination mobility (trips made in order to perform activities within the destination area).

The choice of vacation destination has always been of interest to researchers from tourism marketing and management (Decrop 2006). Understanding these decisions is crucial for tourism-dependent destinations to promote their assets, attract more guests, and as a result, generate more revenue. Therefore, the inter-destination travel patterns have been widely investigated both in theoretical works (Rugg 1973; Sirakaya et al. 1996; SirakayaTurk and Woodside 2005; Woodside and Lysonski 1989) and in numerous case studies (Armstrong and Mok 1995; Eymann and Ronning 1997; LaMondia et al. 2010; van Nostrand et al. 2013). At the same time, the research on the intra-destination movements, i.e. travel within the destination, is relatively limited. As McKercher and Zoltan (2014) argue, the reasons for that are threefold and pertain to the low accuracy of the geolocation data, insufficient resolution of travel-activity data collected from tourists, and lack of a theoretical framework. Only recently, there has been more attention paid to local travel behavior thanks to the use of GPS (Global Positioning System) traces from mobile devices (Shoval et al. 2014; Thimm and Seepold 2016) and GIS (Geographic Information Systems) techniques (Lau and McKercher 2006).

Yet, many of the existing studies are descriptive and focus on visualizing geographical and temporal dimensions of tourist movements or drawing conclusions on itinerary types and frequency of visits (McKercher et al. 2019; Wu and Carson 2008). Lew and McKercher (2006), in the probably first theoretical work on tourist intra-destination travel, provide an extensive breakdown of factors ${ }^{1}$ impacting intra-destination movements of tourists, ranging from tourist time budget to personal characteristics to place knowledge.

Works utilizing mathematical models are much less prevalent so far. However, the topic is slowly acquiring attention of researchers who start applying discrete choice models to quantify travel behavior of tourists and embed them into models. A relatively large study on tourist local travel (over 2000 face-to-face interviews in 29 tourism destinations) was conducted in three regions in Japan by Wu et al. (2011). Applying a latent class modeling framework, they revealed that, except travel time and distance, attractiveness of a destination (measured by number of attractions and number of visitors) is the main factor influencing destination choice, whereas sociodemographic variables (gender, age, marital status) are decisive for the travel party choice. Researchers have also started exploiting GPS data for model building. For instance, Hardy and Aryal (2020) employed neural networks to analyze GPS tracks of tourist movements in a national park in Australia. Based on survey data and GPS tracks, Li et al. (2019) built models of destination choice of tourist visitors to Gulangyu region in China. They observed that tourists who purchased a joint ticket that includes several attractions tend to travel to zones where these attractions are located. Tourists also avoid areas where they have already been to, and areas with poor signage. As far as the intra-destination mobility within the Alpine regions is concerned, Zoltan and McKercher (2014) analyzed visitors' behavior in the Swiss canton of Ticino based on destination card use. Their findings reveal that tourist

\footnotetext{
${ }^{1}$ Many of these factors are used in the design of the survey instrument (Sect. Survey instrument).
} 
movement patterns are defined largely by the spatial dimension rather than through activitybased segmentation. Nevertheless, none of the aforementioned studies distinguishes between movements that are part of tourist activities (e.g. making a hiking trip) and movements to activities (e.g. driving to a zoo), which are of greater importance for transport planning because they cause congestion on roads and crowding in public transportation.

Compared to daily travel, which is largely shaped by trips to primary activities (e.g. work, school) with stable locations that do not change at short notice, the choice set of available destinations during a vacation stay can be a more complex issue. Unlike residents, visitors do not have equal knowledge about the area and may or may not be aware of some of the alternatives (cf. the choice set formation process by Decrop (2010)) depending on whether they have been to the area before, or whether they have researched the available options in advance. Moreover, they usually have no fixed points governing their movement patterns (other than lodging), while residents are tied to the location where they work or take their children to school, which imposes constraints on their choice set. Due to the short nature of the stay, the visitors' choice set can be dynamic and change quickly over time (Crompton 1992), making it even more difficult to recognize it in the models. It can be also be driven by habits, attachments or routine (Björk and Jansson 2008), which contradicts the assumption of tourist's absolute rationality and optimization character of the decision process. For instance, a returning tourist might not consider a new alternative on-site (e.g., a restaurant) since they are used to the one that they have been visiting for the last few years.

Besides tourism, there have also been applications of choice models to leisure trips of domestic populations. For instance, Simma et al. (2002) analyze the destination choice for leisure activities of Swiss residents within Switzerland. Similarly, Juschten and Hössinger (2021) examined the joint choice of destination and transport mode among the Viennese population traveling on summer vacation within Austria. Bhat et al. (2016) apply the Multiple Discrete-Continuous Probit model to study the leisure destination choice of domestic tourists in New Zealand. To the author's knowledge, by far the most comprehensive study dealing with leisure and tourism destination choice specifically in the Alpine regions was conducted for Switzerland by Tschopp et al. (2010). Although the objectives and spatial area of their work are similar to the ones defined in current research, they concentrate merely on the arrival/ departure trips to/from the final destinations for both leisure and tourism purposes. Moreover, their destination choice model for holiday trips is limited only to the winter season (skiing activities) and to the trips of Swiss citizens. An example of a more locally and less state-wide focused study is the one by LaMondia and Bhat (2013), who applied the Multivariate Binary Probit model to study the visitors' leisure travel behavior in Northwest Canada. Scarpa et al. (2008) analyzed the destination choice of members of the Italian Alpine Club (CAI) for oneday outdoor trips in the Alps and discovered that, except travel cost, also difficulty of hiking trails and number of mountain huts influence the decisions, while Scarpa and Thiene (2004) concentrated only on climbers and mountaineers and found travel cost, severity of the environment and number of alpine shelters to be influential factors.

\section{Mode choice on vacation}

Although transport mode choice is relatively well represented in tourism literature, studies using discrete choice methods are very scarce. Much research with discrete choice has been done in the fields of tourism demand (Morley 2012), significantly less in long-haul tourism destination choice (LaMondia et al. 2010) and very little in modeling transport mode choice (Thrane 2015). 
Transport mode choice is strongly dependent on the destination choice and hence they should be considered and modeled jointly, which has been repeatedly demanded in the literature (LaMondia et al. 2010; Masiero and Zoltan 2013). Clearly, the decision about transport mode choice for local trips within the vacation region depends strongly on the initial decision about transport mode for long-distance trip to the destination (Bieland et al. 2017; Gross and Grimm 2018). However, this relationship also works the other way around-the choice of transport mode for travel to the destination can be driven by factors related to on-site mobility. Visitors decide to travel to Alpine regions by car for fear of insufficient mobility at their destination and inflexibility of public transportation (Bursa and Mailer 2018). In such a case, private car provides a high degree of independence and usually ensures the most effective utilization of time. Luggage transport is another factor deterring tourists from choosing transport mode other than car for their vacation trip (Böhler et al. 2006).

As far as the intra-destination mobility of tourists is concerned, a broad description of factors is included in Le-Klähn and Hall (2013). They found out that lack of information and personal preferences are the most common explanations for not using transit services in rural tourism sites. Additionally, not every single tourist spot in rural regions is accessible by public transport, which discourages the exploration-focused tourists from relying only on public transport services on-site. In urban areas on the other hand, tourists value the ease of use, efficiency and personal safety when choosing public transport, and parking facilities when driving private car, as Thompson and Schofield (2007) point out. Dickinson and Robbins (2008) also narrowed their research to rural destinations. In addition to general convenience and need to carry equipment as the main reasons for choosing private car, they also highlight a strong car attachment of some visitors who do not even consider alternatives no matter their availability, price, or other attributes. Gross and Grimm, in their review paper (2018), synthesized outcomes of many existing studies and found that, above all, sociodemographic factors, transport mode for travel to the destination, travel duration and travel cost, and type of vacation (organized or individual travel) play a role in transport mode choice at the destination. The potential influence of weather is discussed separately in Sect. 2.6.

Within the alpine setting, specific factors affecting transport mode choice for the longdistance travel as well as for trips at the destination have been investigated by Rüger and Mailer (2020) and Bieger and Laesser (2013), who revealed that the family/group size and transport of sport luggage (e.g., skiing equipment, mountain bike) is dominant in the decision process, particularly in the winter season. Masiero and Zoltan (2013) applied a probit model for the mode choice of tourists in the Swiss canton of Ticino and observed, among other things, that domestic tourists and returning visitors (i.e. tourists who have been to the region before) are more likely to use public transportation, whereas older tourists and male tourists are more inclined to use private cars. The work by Pettebone et al. (2011) provides insights into mode choice at the destination from an American perspective. They found that visitors to the Rocky Mountain National Park are willing to switch from private car to shuttle bus if it enhances their chances of being in the park with fewer other people.

Unfortunately, none of the existing studies analyzed the importance of travel time and travel cost for the transport mode choice of tourists traveling within the destination in a quantitative way, which is a distinct gap in the research, making it impossible to apply a monetary measure to improvements or deteriorations in attributes of the available modes (e.g. higher transit frequency or longer travel time). 


\section{Route choice on vacation}

Route choice is another element of the set of decisions that have to be made when planning a trip. The majority of studies on route choice behavior to date have concentrated on dense urban networks. This is understandable because these are the most challenging environments - urban networks are large, multimodal and the route choice plays a significant role in traffic management. In contrast, research on route choice in non-urban areas is very scarce. Tourism researchers address the topic from the perspective of destination management and roadside tourism facilities (Denstadli and Jacobsen 2011), which is unusable for transport modeling purposes. However, they provide some interesting observations about how tourists differ in their route choice behavior from local residents, which should be considered when developing models of tourist route choice.

Lew and McKercher (2006) have raised the issue of tourists not possessing full knowledge about the transport system in the region they visit. They highlight the influence of topography on transport networks in mountainous regions, which makes the whole route choice process unlike in flat areas (shortest/fastest route). They also mention the factor of picturesqueness of routes that often prevails over travel time or distance when choosing a route to the destination or moving around within the destination. This is in line with Jacobsen (1996) who discovered that the views and landscape experience are cherished by motor tourists surveyed in Norway. The component of visual attractiveness of a route plays a particularly important role on discretionary (i.e. non-work) trips, according to Ben-Akiva et al. (1984), who found that the disutility of travel time on non-scenic roads is about five times the disutility of travel time on scenic roads. Problematic is however how to define picturesqueness and how to quantify the scenic attributes of a route. Alivand et al. (2015) developed a very promising approach capable of computing scenery-related attributes ranging from road curviness to the viewshed from the road elements using data from different sources and providers e.g. volunteered geographic information (VGI), digital terrain model (DTM), TomTom, Panoramio geo-tagged photos, Google Earth, census data etc. They found that an increased presence of water bodies, mountains, forests and parks along a route positively contributes to the probability of choosing it as a scenic route, whilst urban areas along the route decrease this probability.

The common use of the built-in and external GPS navigation devices among tourists should not be neglected. In the context of car use, it is supposed to lead to tourists sometimes having even better knowledge about traffic conditions than local residents, who rely on their habits, common sense and heuristics (Prato et al. 2012). This, however, does not (yet) apply to the knowledge about parking facilities at tourist attractions.

Yet, routing decisions of travelers in mountain regions have not been analyzed by scholars so far. Presumably because alpine network systems provide limited routing alternatives. However, the valuation of the route's visual component as well as its windingness, steepness and the resulting difficulty to drive may be influential on visitors' other travel choices. In particular, the attractiveness of the route and the corresponding travel experience may lead to the phenomenon of undirected travel "...in which travel is not a byproduct of the activity but itself constitutes the activity” (Mokhtarian et al. 2001; Mokhtarian and Salomon 2001). In other words, visitors might opt for car to be able to drive the scenic roads and stop for taking photos or choose train to observe nature from its panoramic windows. That is, they treat the ride itself as part of the vacation experience, not just the unpleasant necessity of relocation from $\mathrm{A}$ to $\mathrm{B}$, which is a valid concept in daily commute (Singleton 2020). 


\section{Impact of weather}

Typical activities performed by tourists in mountain regions, e.g. hiking, climbing, cycling or skiing, are obviously weather-dependent. It can be argued that if the participation in an activity is weather-dependent, then the choice of location where the activity is conducted and the choice of transport mode used to reach that location may be affected by weather too. It is therefore worth investigating how and to what extent tourists at destinations adapt their travel behavior to (unfavorable) weather conditions and whether they react differently than at home. This section provides an overview of what is already known in terms of weather effects on various facets of transportation and tourism.

In the context of everyday travel, there is abundant evidence that precipitation correlates positively with congestion and accident frequency (Andrey et al. 2003; Golob and Recker 2003). It also negatively affects the performance of transportation networks and traffic flow and thus travel time and travel time reliability (Maze et al. 2006), yielding larger effects of snowfall than of rainfall (Hranac et al. 2006). But, as Koetse and Rietveld (2009) conclude in their review paper, the average effects of weather on traffic volume, daily travel and commute patterns are of low magnitude and compensate each other in the long run (more leisure trips thanks to higher temperatures; less leisure trips due to longer heavy rains). There is, however, more clear evidence at the level of specific transport modes and instantaneous response of travelers to adverse weather. In particular, the use frequency of active modes—cycling and walking-decreases significantly in the presence of rain, very low or very high temperatures and strong wind (Sabir 2011; Saneinejad et al. 2012). In the case of cycling, the effect is remarkably large for leisure trips, while bicycle commuters are more weather resistant (Heinen et al. 2010; Liu et al. 2015). Compared to cycling, walking starts to become weather-sensitive in case of a very sharp temperature drop or very intense rain. Studies on weather effects on the choice of private car and public transportation provide weaker outcomes than for active modes. In urban environments, adverse weather interacts strongly with other attributes such as traffic congestion, crowding and punctuality of transit, and the effects differ between cities, days of the week and population segments (Anta et al. 2016). In general, however, there is a distinct shift from walking and cycling to driving and transit in case of rain or snow (Sabir 2011).

The influence of weather on tourism cannot be neglected, since the whole industry relies to a great extent on "good weather" (Day et al. 2013). Heavy rains, heat waves and frequent storms of increasing severity can negatively affect local tourism markets. Also mountain regions have to face challenges and risks induced by climate change such as increasing snow uncertainty in winter and the resulting decline in demand (Elsasser and Bürki 2002; Gössling and Hall 2006; Koenig and Abegg 1997), or extended summer seasons leading to intense traffic on alpine roads and mountain passes (Cavallaro et al. 2017). However, the evidence on if and how tourists' weather experiences influence their behavior is complex, ambiguous and segment- and region-dependent (Gössling et al. 2012). While, in general, weather is considered one of the strongest destination attributes and one of the most powerful motivators for tourism (Kozak 2002), it must not always be a decisive factor. As far as the planning stage is concerned, according to Pröbstl-Haider et al. (2015), tourists may not perceive weather as a determinative decision component when choosing an alpine summer destination, as other factors (e.g. leisure attractions) often play a more important role. In terms of the effect during the 
stay, both Scott et al. (2008) and Steiger et al. (2016) found the absence of rain to be particularly important for visitors to mountain areas and their overall satisfaction, with a caveat that there are large differences between age groups, nationalities or first-time and returning tourists. However, satisfaction levels might not necessarily be reflected in the real behavior, and the nature of the visit as well as the attraction mix must be considered. McKercher et al. (2014) analyzed the GPS tracks of visitors to Hong Kong and found that urban tourists are rather indifferent to weather, in particular if they are staying only for a short period or on a tight budget. Similar resilience to weather, increasing with the length of stay, was found among campers in Canada (Hewer et al. 2017). Also in non-urban settings-as Becken and Wilson (2013) argue in their case study of New Zealand-tourists may have a great dose of understanding and acceptance of inclement weather, in particular if they are aware of and prepared for the unstable and variable weather that often occurs on New Zealand's islands (which is also the case of the Alps in Europe). They do not search for the most optimal choice, but rather proceed with the plan unless some threshold is exceeded and the weather turns very unappealing. However, whether the same holds for tourists' short-term transport mode choices or whether the effects of precipitation and temperature on choosing active transport modes are of the same magnitude as known from studies on everyday mobility remains unexplored.

\section{Survey design}

Researchers conducting studies on daily travel behavior usually have good-quality datasets at their disposal (see for example Aschauer et al. (2018) and Sammer et al. (2011) for Austria, Axhausen et al. (2000) for Germany, Bundesamt für Statistik (BFS) (2017) for Switzerland, NatCen Social Research (2019) for the UK and Federal Highway Administration (2017) for the US). These studies deal with local populations and serve as a basis for creating policies at regional or national levels. Consequently, government departments and agencies provide funding to ensure sufficient sample size and thus representative results.

This is not the case in tourist travel, which, despite being responsible for a substantial part of transport problems in countries with developed tourism industries (e.g. Austria, Italy, Switzerland), does not receive enough attention from policy-makers.

This study proposes a trade-off and attempts to achieve an acceptable sample size with a limited budget. By asking respondents to report on two days of their stay, fewer people need to be interviewed, which is very time-consuming and costly in the case of tourists. At the same time, limiting the diary length to two days keeps the response burden at a moderate level.

\section{Travel pattern of a tourist}

The conceptual representation of a full travel pattern of a tourist is given in Fig. 1. In its simplest form (i.e. no "road-trip" with multiple destinations), it is comprised of:

- Long-distance trip from home to the destination.

- At least one-night-long stay at the destination, during which activities are performed and tours are made.

- Long-distance return trip home. 


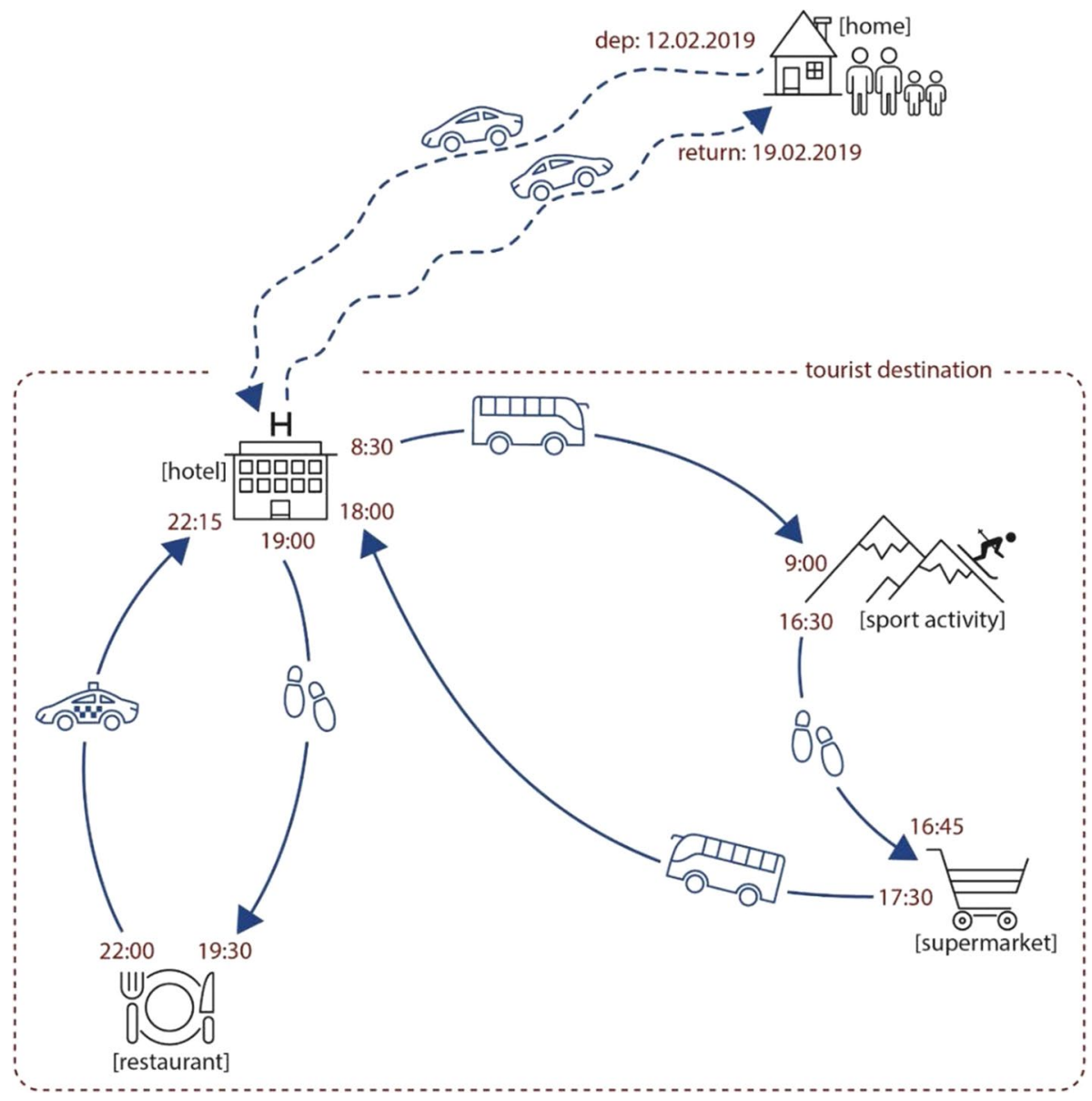

Fig. 1 Example of a tourist daily schedule with arrival and return trips to and from a tourist destination

\section{Survey location}

Three tourist regions were selected as locations for data collection: the Ötztal valley, the Zillertal valley and the region Hohe Salve. All three are located in the province of Tyrol in Austria (Figs. 2 and 3) and are characterized by extensive tourism industry (Table 1).

\section{Survey methods}

Despite the benefits of automated and semi-automated data collection methods based on GPS (as described in Sect. 2.2 and by Prelipcean et al. (2018)) and obvious drawbacks resulting from using a memory-based approach, the survey was designed as a revealed preference (RP) single cross-sectional survey in two forms: as a PAPI (Paper-and-Pencil 


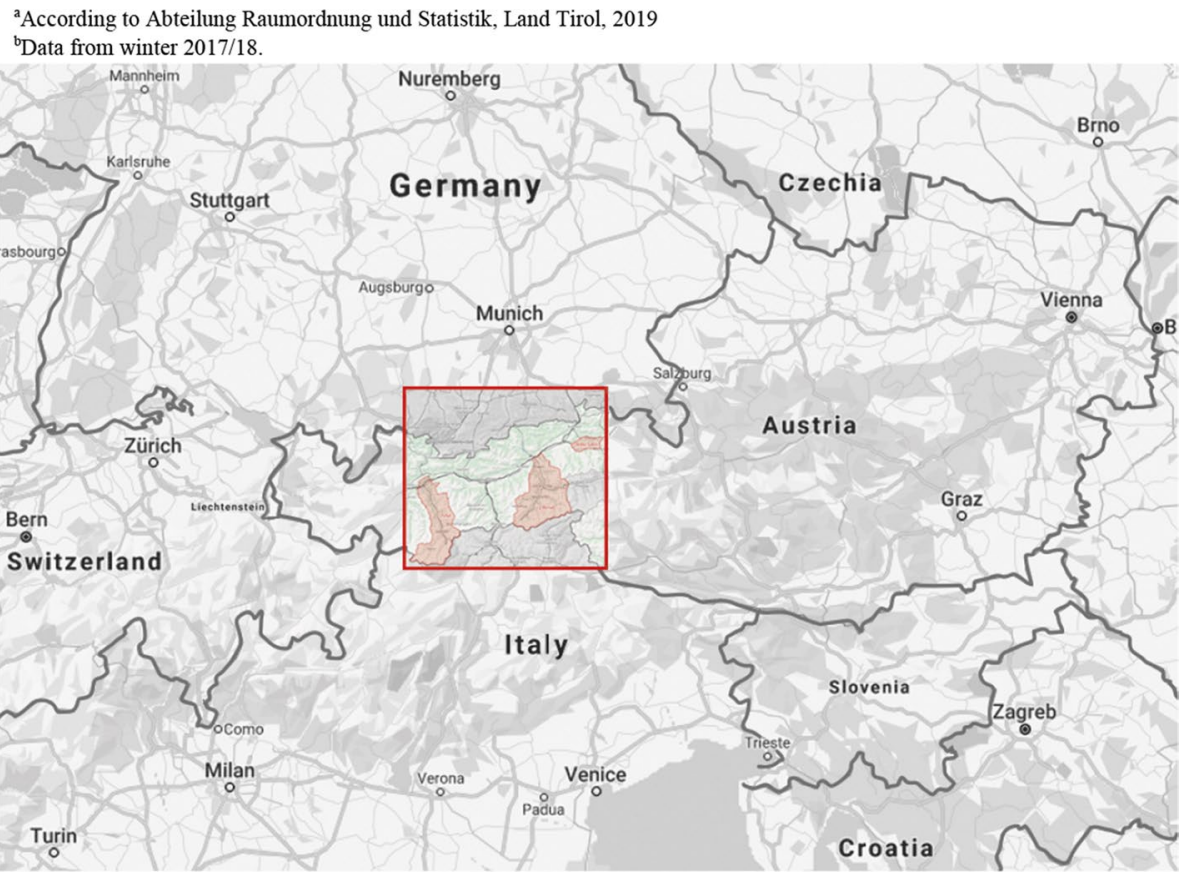

Fig. 2 Location of the study area on the map of Austria and its neighboring countries. Red-colored rectangle is presented in detail in Fig. 3

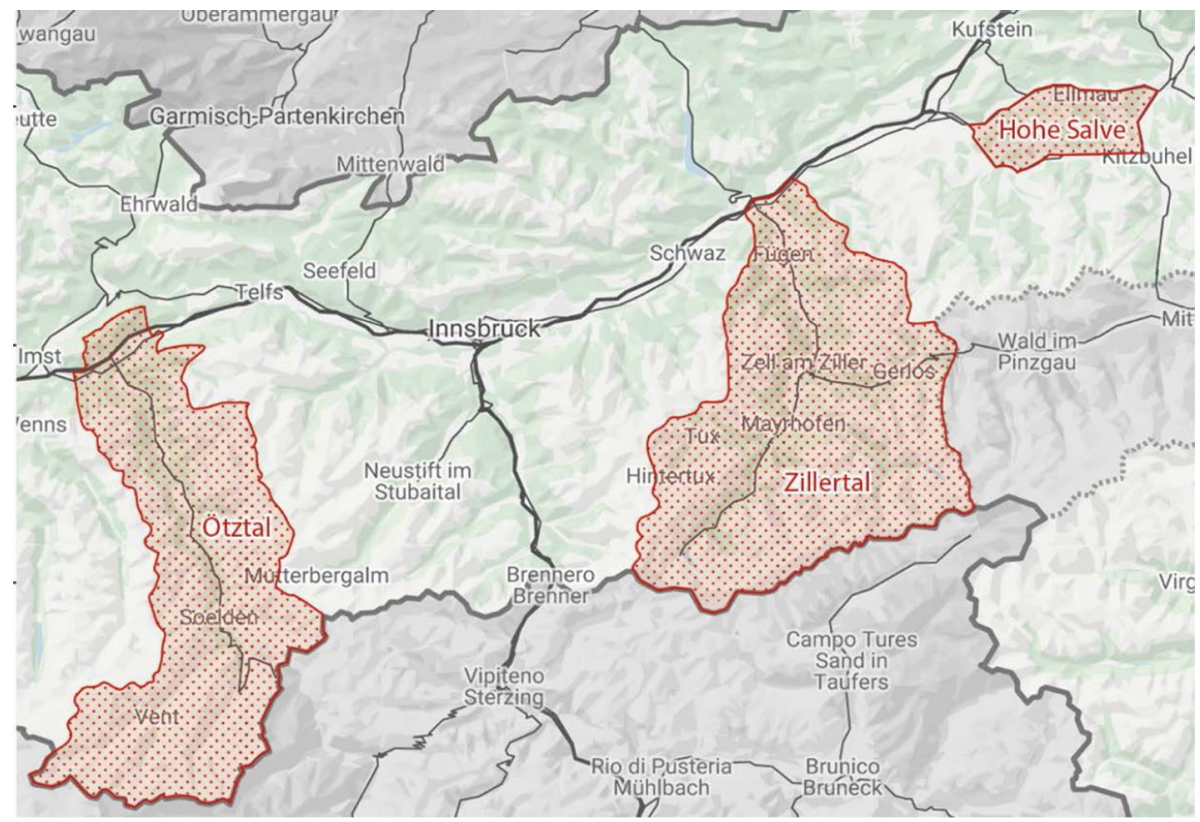

Fig. 3 Location of the tourist regions Ötztal, Zillertal and Hohe Salve (red dotted areas) in the province of Tyrol (color map) in Austria 
Table 1 Characteristics of the survey regions ${ }^{\mathrm{a}}$

\begin{tabular}{lrrr}
\hline & Ötztal & Zillertal & Hohe Salve \\
\hline Area $\left[\mathrm{km}^{2}\right]$ & 881 & 1098 & 217 \\
Residents & 18,277 & 37,140 & 15,931 \\
Accommodations & 309 & 467 & 45 \\
Beds $^{\mathrm{b}}$ & 27,865 & 51,457 & 5,826 \\
Ski resorts & 6 & 4 & 1 \\
Ski slopes length [km] & 326 & 535 & 258 \\
Arrivals - Summer 2019 & 358,079 & 666,054 & 76,766 \\
Overnights-Summer 2019 & $1,248,163$ & $2,830,628$ & 296,530 \\
Arrivals-Winter 2018/19 & 618,600 & 882,405 & 66,459 \\
Overnights-Winter 2018/19 & $2,903,563$ & $4,584,125$ & 312,437 \\
\hline
\end{tabular}

${ }^{a}$ According to Abteilung Raumordnung und Statistik, Land Tirol, 2019

${ }^{b}$ Data from winter 2017/18

Interview) survey and CAPI (Computer Assisted Personal Interview) survey conducted with tablet computers.

The choice of these instruments is justified by the characteristics of today's tourists, who prefer shorter but more frequent stays and booking on short notice, which results in organizational difficulty to contact them before the study, equip them with automated devices, instruct and advise during the study and collect the devices before they return home. Furthermore, the burden concerning software deployment for semi-automated measurements with smartphones was too large for the study.

The initial plan was to conduct the survey exclusively using self-administered PAPI questionnaires distributed in accommodations in the three regions, following the principles proposed by Cambridge Systematics Inc. (1996). This approach would have facilitated the control over the sampling process. However, recruiting the hotels to participate in the survey turned out to be a major hurdle. The only successful way to approach the hotel owners about the project was through the local DMO. The DMO employees knew which hoteliers in the area could be potentially willing to cooperate and were capable of convincing some of them to participate. Contacting them directly was ineffective and resulted in refusals justified by lack of time or human resources and concerns about disturbing guests during their vacation time (cf. Tschopp et al. 2010). All in all, however, the response rate proved extremely low (see Sect. 3.5) and hence the survey method was changed to assisted PAPI and CAPI interviews conducted on-site in highly frequented locations spread over the valleys:

- Ski lodges, bars and restaurants.

- Local hot-spots such as amusement parks, wellness and spa centers, hot springs.

- Recreation facilities such as lakes, parks and playgrounds.

- Sport facilities such as mountain bike trails, hiking paths.

This change resulted in a loss of control over the sampling - a pure convenience sampling was now used. It inevitably implies that the results from the sample cannot be easily generalized to the entire study population (Lavrakas 2008; Sirakaya-Turk et al. 2017).

A team of trained interviewers conducted interviews on selected days during the winter and summer peak season at various tourist sites. Both fully and partially assisted 
interviewing methods were tested. In the latter method, the interviewers assisted more than one person at a time and switched to a fully assisted personal interview only when they noticed difficulties or someone giving low-quality answers.

In the on-site survey, incentives proved ineffective, which to some extent contradicts what is known from the literature (Simmons and Wilmot 2004; Singer and Ye 2012; Tooley 1996). However, studies on the impact of incentives have so far concentrated only on household surveys. Both monetary (5 EUR banknotes) and non-monetary (promotional items) incentives were tested. We could observe that, although incentives convinced some negatively oriented guests to fill out the questionnaire (which they presumably would not have done otherwise), the quality of their answers was low (blank fields, inadequate answers). On the other hand, among the positively oriented tourists, the motivation to fill out the questionnaire and the quality of their answers was not affected by the incentives, as they were willing participate anyway.

Regarding the quality of responses, despite the attached instructions for filling out the questionnaire as well as an example of a filled diary, respondents struggled to distinguish between trips and activities. Due to a high response burden, dropouts were not uncommon while filling out the questionnaire.

We argue that only a fully assisted interview and completing the questionnaire in the constant presence of the interviewer can guarantee good-quality results. Tourists approached in local tourist hotspots such as ski lodges must fill out the questionnaire in limited time (lunch break) and space (small tables) and under generally inconvenient conditions (children interrupting, wet clothes). This is a completely different environment compared to household surveys, where respondents can choose a suitable place, moment and take their time (e.g., to read the instructions). Additionally, various interaction techniques had to be used so as not to deter guests from completing the lengthy questionnaire, such as approaching only selectively chosen tables or approaching children first, who then, if they find it entertaining, convince parents to participate.

\section{Survey instrument}

Three fundamental parts constitute the survey instrument:

- Personal questions.

- Questions about the stay and travel to the destination.

- Activity diary.

In addition to these elements, the questionnaire also contained text informing the respondent about purpose of the research, research team, processing of personal data, and estimated time for completing the survey. Further, the paper questionnaire contained instructions for answering the questionnaire and an example of a completed diary. Figures 17 to 20 in the appendix present the physical design of the paper questionnaires used in the PAPI survey. The CAPI forms were implemented in the SoSci Survey on-line system (Leiner 2020) and have an identical content. The survey instrument was prepared in both English and German. The following sections describe the content of the questionnaire and provide reasoning for the selection of questions. 


\section{Personal questions}

According to Crawford et al. (1991) and Godbey et al. (2010), participation in leisure activities is subject to intrapersonal, interpersonal and structural constraints. Therefore, in this section, data on factors constituting these constraints were collected using variables such as gender, age, nationality, education/employment status, age and number of children, health/fitness level and car availability.

The selected tourist regions of Ötztal, Zillertal and Hohe Salve are very sport-oriented, both in winter and in summer. While information on sport activity of tourists during their stay is collected through the activity diary, our questionnaire also collects data on guests' physical activity at home. It is argued that frequency of sport activities in daily life influences sport-related behavior on vacation (De Knop 2007).

\section{Questions about the stay and travel to the destination}

Lew and McKercher (2006) have classified the factors influencing local travel behavior of tourists into three categories:

- The size and expenditure of tourist time budget.

- Personal motivations, interests and travel group composition.

- Tourist knowledge of the destination.

In this section, respondents were asked basic questions about the length of stay, exact place of stay, travel party composition and transport mode used for travel to the destination. By collecting information on the exact arrival and departure dates of visitors, one can analyze the effect of the (fixed) length of stay, as well as the effect of the (varying) moment of the stay, represented by the elapsed fraction of stay. This is driven by two hypotheses. The first one posits that with the vacation days going by, people are becoming more relaxed, ${ }^{2}$ and hence, may react less negatively to travel time. Their positive attitude might also follow a non-linear curve, as proposed by Lin et al. (2014), reaching its peak around the middle of the stay. The second one assumes the opposite-visitors are becoming more stressed and impatient and hence are reacting more negatively, which would be in line with the findings of Nawijn et al. (2013).

According to LaMondia and Bhat (2013), tourists tend to have a main purpose characterizing the long-distance activity component of their holiday trip, which then drives them to choose a particular destination and particular activities. The topic of holiday and leisure motivations has been intensively studied by many researchers who developed different measurement scales and items (Beard and Ragheb 1983; Crompton 1979; Iso-Ahola 1984; Ryan and Glendon 1998). Given the restricted space in the questionnaire, eight predefined purpose categories were proposed (see the Appendix).

According to Lehto et al. (2004), whether a tourist has visited a destination before or it is their first visit, affects their knowledge about the destination (activities and attractions, local transportation), which ultimately influences their activity and travel choices onsite. The same applies to whether a destination is the main and only place of stay during

\footnotetext{
2 The phenomenon of positive vacation effect on travelers' happiness and well-being is widely researched and its existence is confirmed (see for example Gilbert and Abdullah (2004) and Sirgy et al. (2011)). There is, however, no consensus on its dynamics over the course of the vacation stay. Nor is there any work so far that studied this phenomenon in the context of perception of travel time or travel cost.
} 
vacation or is it one of many stops. A touring trip implies different on-site behavior than stationary vacation (Lew and McKercher 2006). Questions regarding these two aspects have been incorporated in the survey.

The information search behavior is considered crucial for tourists' knowledge about the destination (Bieger and Laesser 2016; Fodness and Murray 1999; Gursoy and McCleary 2004; Klassen 2001). Therefore, two additional questions were asked, aiming to find out how, if at all, visitors inform themselves in advance about the journey to the destination and about the mobility on-site.

\section{Activity diary}

The travel-activity diary operates on a selection of terms proposed by Axhausen (2008), that is, trip, tour and activity. An activity-oriented approach was applied for the design of the diary, since it is the activities, not trips that are of greater importance and interest for people during vacation, and hence should prove more effective for the respondents to recall their movements. All travel data was collected at the resolution of trips. Stages (trip legs) were ignored in the survey.

In the activity diary, the respondents were asked to give information on all the activities that they performed out of their accommodation during two days of their stay. The diary included questions on the exact type and location of the activity, start/end time, as well as expenses, company and the influence of weather on the activity choice. Furthermore, information about trips made between the activities was collected, including transport mode, cost, company, impact of weather etc. The activities performed at the accommodation were disregarded, since they do not induce any travel in the transport network.

The design of the diary draws from the existing well-established examples of household travel surveys (HTS) including the American NHTS (National Household Travel Survey) (Federal Highway Administration 2017), the German Mobidrive (Axhausen et al., 2000) as well as the Austrian Österreich Unterwegs (Sammer et al. 2011) and MAED (MobilityActivity-Expenditure-Diary) (Aschauer et al. 2018), all based on the trusted New KONTIV Design (Brög, 2009), and transposes them into the field of tourism. So as to keep the response burden in the PAPI survey low, the activity diary for two days along with personal, situational and preference questions was fit on a single A3 sheet (half-fold). The PAPI diary takes $50 \%$ of the questionnaire (two A4 pages) and provides space for 7 activities and 8 trips per day. In the case of the CAPI survey, the on-line questionnaire included exactly the same questions as the paper version. Automated rules controlled the data quality, correctness of variable types and detected missing answers. This, together with the positive effect of the interviewers conducting the CAPI survey, resulted in noticeably better quality of the collected data.

In contrast to typical HTS questionnaires, we decided not to provide any predefined activity types in the questionnaire. While reliable and validated categories have been developed for daily activities (e.g., work, education, pick-up/drop-off, shopping, leisure), it is very difficult to create categories for all possible leisure activities (although there are some attempts, see Lanzendorf (2002)). Therefore, it is common to ask the respondent for their own detailed description of the performed activity (Axhausen 2015) and classify it afterwards.

With regard to the influence of weather on the activity and mode choice, the respondents were asked to indicate whether they chose the activity/mode that they had planned to choose or whether they had to choose another ("plan B") activity/mode because of the 
(unfavorable) weather. This novel approach makes it possible to directly capture the impact of weather on every decision made during the reported day. In combination with historical weather measurement data for the survey dates, it is a very powerful dataset. In the few existing studies (Liu et al. 2016; Termida et al. 2016), only the information on subjective weather perception on a given day was collected.

\section{Survey participation and response burden}

As long as the choice and wording of survey questions and the definition of the survey area were relatively comprehensive and manageable tasks, the actual implementation of the survey in a tourist region was a much more complex undertaking. The most difficult issues included the choice of the survey method, distribution method for the PAPI questionnaires, arranging meetings with accommodation providers, convincing them to participate in the project, defining incentives and finding a way to reach out to guests in the field and to overcome their participation and response burden. A summary of these efforts is provided in Table 2.

For the paper questionnaire with a travel-activity diary for two days, the total response burden was calculated following the methodology by Axhausen et al. (2015). In the minimum scenario of only one activity and two trips per day, the response burden is 381 , whereas the maximum case of seven activities and eight trips (all boxes filled) results in a response burden of 1309. Employing their regression equation, one would expect a response rate of $8.00-24.35 \%$ respectively.

Out of the 640 questionnaires (270 in English, 370 in German) distributed in the hotels during the winter season, only 28 were returned, yielding an average response rate of $4.4 \%$. It is below the lower bound of the range estimated using the method by Axhausen et al. (2015). Potential reasons for that are:

- Difficulties in recruiting hotels for the study that are truly willing to cooperate.

- No control over if, how, when and to whom the questionnaires were distributed after they were handed over to the hotel.

- Possibly negative mediating role of the reception staff (not all questionnaires were distributed; guests were not sufficiently encouraged to participate).

- Questionnaires were lost in several cases.

In the face of a very low response rate, the remaining part of the PAPI survey was conducted in form of (semi-) assisted interviews where dropouts were no longer noted. There were refusals when interviewers approached potential respondents, but interviewers were not obliged to report this. In the CAPI survey, which was also conducted in the form of an interview as well, all started interviews were completed, and denials were not reported.

\section{Descriptive analysis}

\section{Complementary datasets}

The survey results comprise the primary data source used in the paper. These data are complemented by following secondary datasets: 


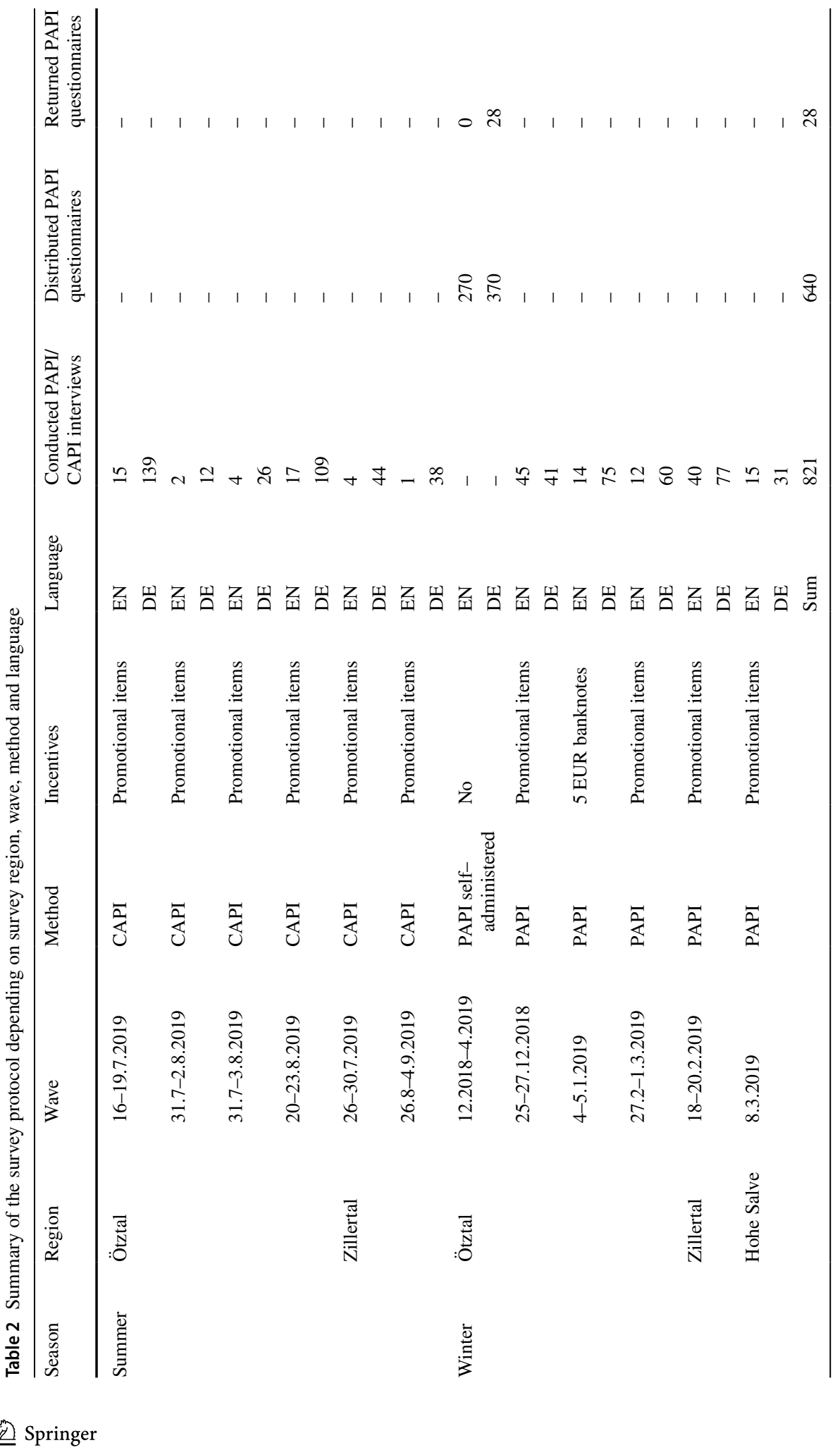


- Historical weather data.

- Geodata from Google Maps API.

- Geodata from the regional transportation model.

- Accommodation data from booking systems of the tourist regions.

Historical weather data were obtained from the Central Institution for Meteorology and Geodynamics (Zentralanstalt für Meteorologie und Geodynamik, ZAMG) in Austria. The data include measurements of air temperature, precipitation, cloud cover, wind speed and snow depth, and were collected at one-hour resolution from following six monitoring stations:

- Haiming, $669 \mathrm{~m}$ a.s.l.

- Umhausen, $1035 \mathrm{~m}$ a.s.1.

- Obergurgl, $1942 \mathrm{~m}$ a.s.l.

- Mayrhofen, $640 \mathrm{~m}$ a.s.1.

- Söll, 697 m a.s.l.

- Innsbruck, $578 \mathrm{~m}$ a.s.1.

Information about lodging comprises:

- object type (hotel, guesthouse, apartment, camping).

- standard (only for hotels, represented by star rating).

- price per person per night (in EUR) in summer and winter.

- price per room/apartment per night (in EUR) in summer and winter.

\section{Data cleansing}

In order not to lose valuable observations where only few items were missing, it was necessary to impute the missing data. The multiple imputation method was chosen (van Buuren 2018), as it delivers less biased results than the ad-hoc solutions (e.g. mean imputation) (Andridge and Little 2010). The missForest package for $R$ (Stekhoven and Bühlmann 2012) was used for the following variables: income, age, gender, education, employment, country of residence, nationality, car availability, car use frequency, driver's license possession, main transport mode for travel to the destination, main purpose of stay, number of adults in household, number of children under 6 , number of children aged 6 to 17, length of the stay, knowledge about travel options to the destination, knowledge about on-site mobility, sport frequency, time spent on sport,, and hotel-related variables. The results presented in the following sections are based on data after the imputation process.

Regardless of the data imputation, following exclusion rules were employed:

- The only respondent from a group/family is below 18 (assumed not to be the decisionmaker in a family/group).

- Respondent's place of stay is outside the study area.

- The answer quality is unacceptable (contradictory answers, misunderstood questions).

As a result, out of 849 questionnaires 224 were eliminated (predominantly PAPI questionnaires from winter) and 625 remained (388 in summer and 237 in winter) (Table 3). 
Table 3 Valid responses depending on survey method and season

\begin{tabular}{llllll}
\hline Share of responses & \multicolumn{2}{l}{ Summer } & & \multicolumn{2}{l}{ Winter } \\
\cline { 2 - 3 } & Number & $\%$ & & Number & $\%$ \\
\hline Self-administered PAPI & 0 & 0 & & 25 & 10.5 \\
PAPI & 0 & 0 & & 212 & 89.5 \\
CAPI & 388 & 100 & & 0 & 0 \\
Sum per season & 388 & 62.1 & & 237 & 37.9 \\
Sum total & 625 & & & \\
\hline
\end{tabular}

The descriptive results are reported at the level of individual respondents (unless otherwise specified).

\section{Characteristics of the respondents}

\section{Socio-demographics}

Table 4 provides a statistical summary (group frequencies and mean values) of the respondents' sociodemographic characteristics from the summer and winter survey periods.

There are notable differences between the seasons. Winter tourists are substantially younger and better educated. They are also more professionally active and possess higher incomes. Their health is better, possibly because they are more physically active. Summer visitors on the other hand are older, less educated, often already retired or working parttime. They have less disposable income, lower car availability and use private cars less often than winter guests. Visitors from Germany dominate in both seasons. Noteworthy, they are followed by Austrian domestic tourists in summer, whilst in winter Dutch tourists come in second place.

Figure 4 illustrates correlations between selected sociodemographic variables. The categorical variables with a self-explanatory order of levels, that is, education, employment, income, and health, were transformed into numeric variables, assuming the lowest level equals 1 and all higher levels are equidistant.

\section{Stay and travel to the destination}

Responses to questions concerning the stay and travel to the destination (part 2 of the questionnaire) are summarized in Table 5.

Overall, summer stays are longer than winter stays. The high standard deviation suggests a wide spread of stay durations in summer. In winter, the length of stay oscillates around 6-7 overnights, which corresponds to a typical holiday week that starts and ends on a Saturday. A winter tourist is accompanied by more household members. Both summer and winter tourists prefer individually organized holidays, which comprise around $85 \%$ of all stays. In over $50 \%$ cases they have already been to Tyrol before. Winter stays are predominantly stationary, whereas in summer, a $15 \%$ share of respondents declare being on a road trip and moving to another place soon. An average winter tourist comes to almost $80 \%$ for sport and recreation, while a summer visitor is attracted similarly by sport (37\%) and rest and relaxation (30\%), followed by social and health purposes. 


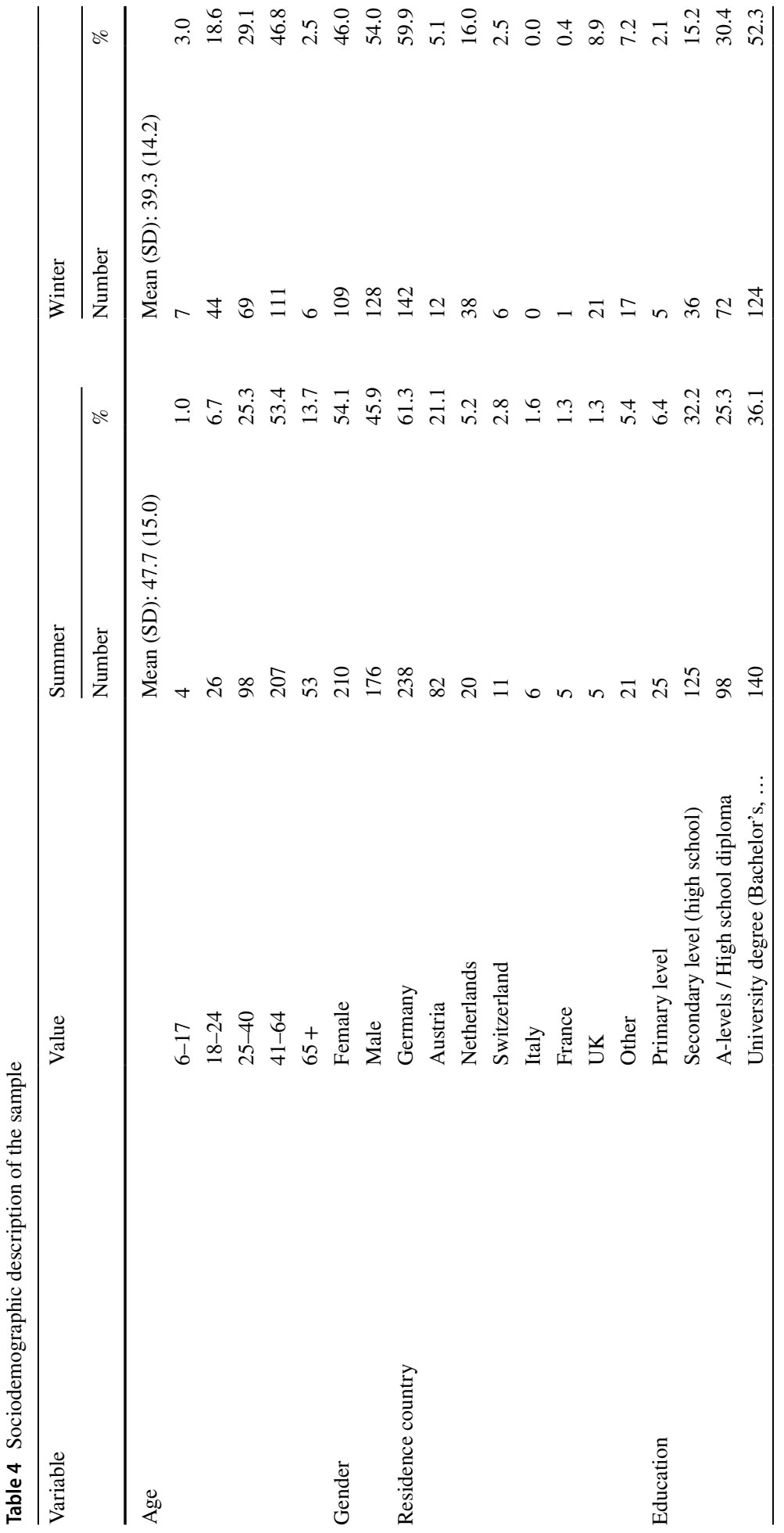




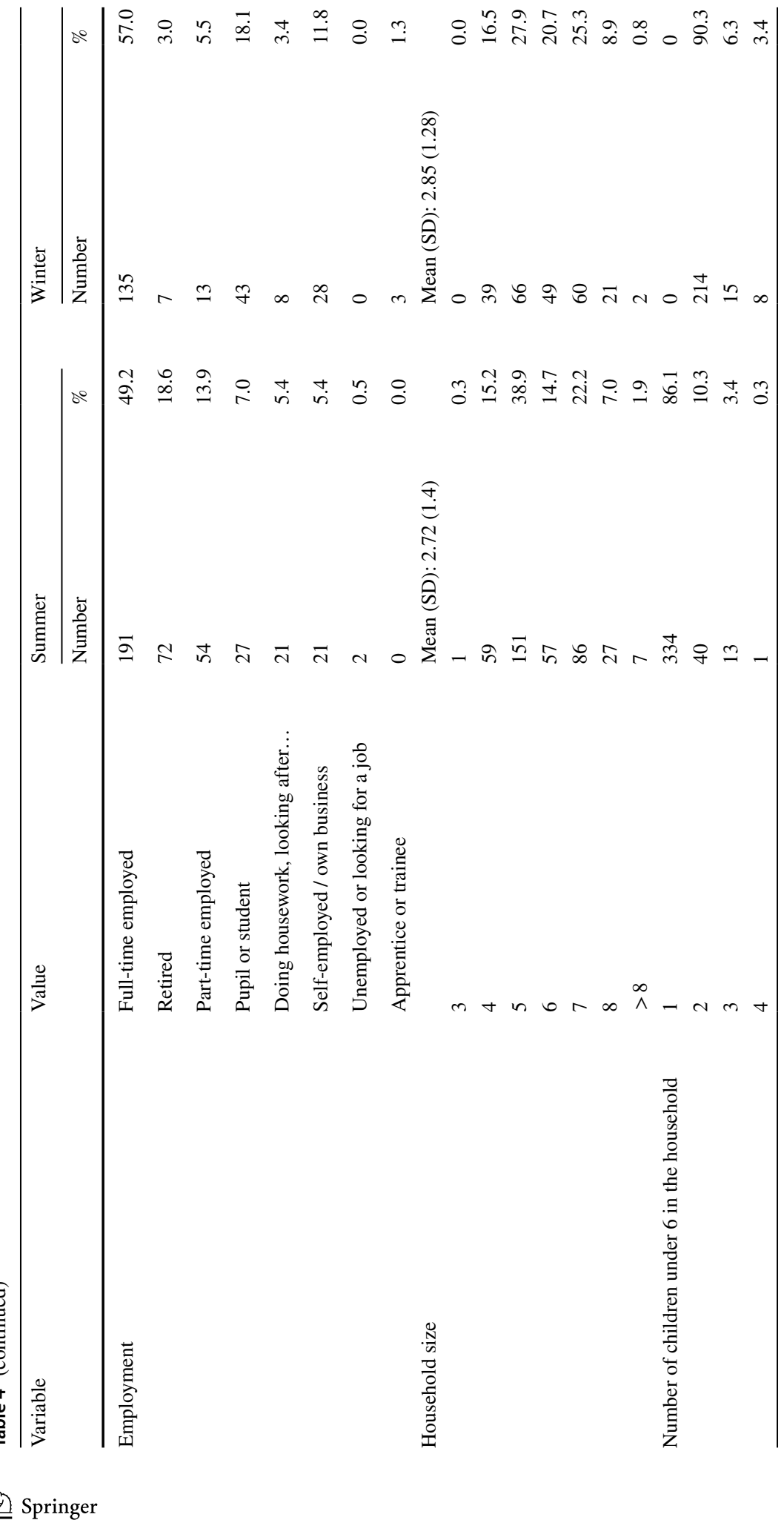




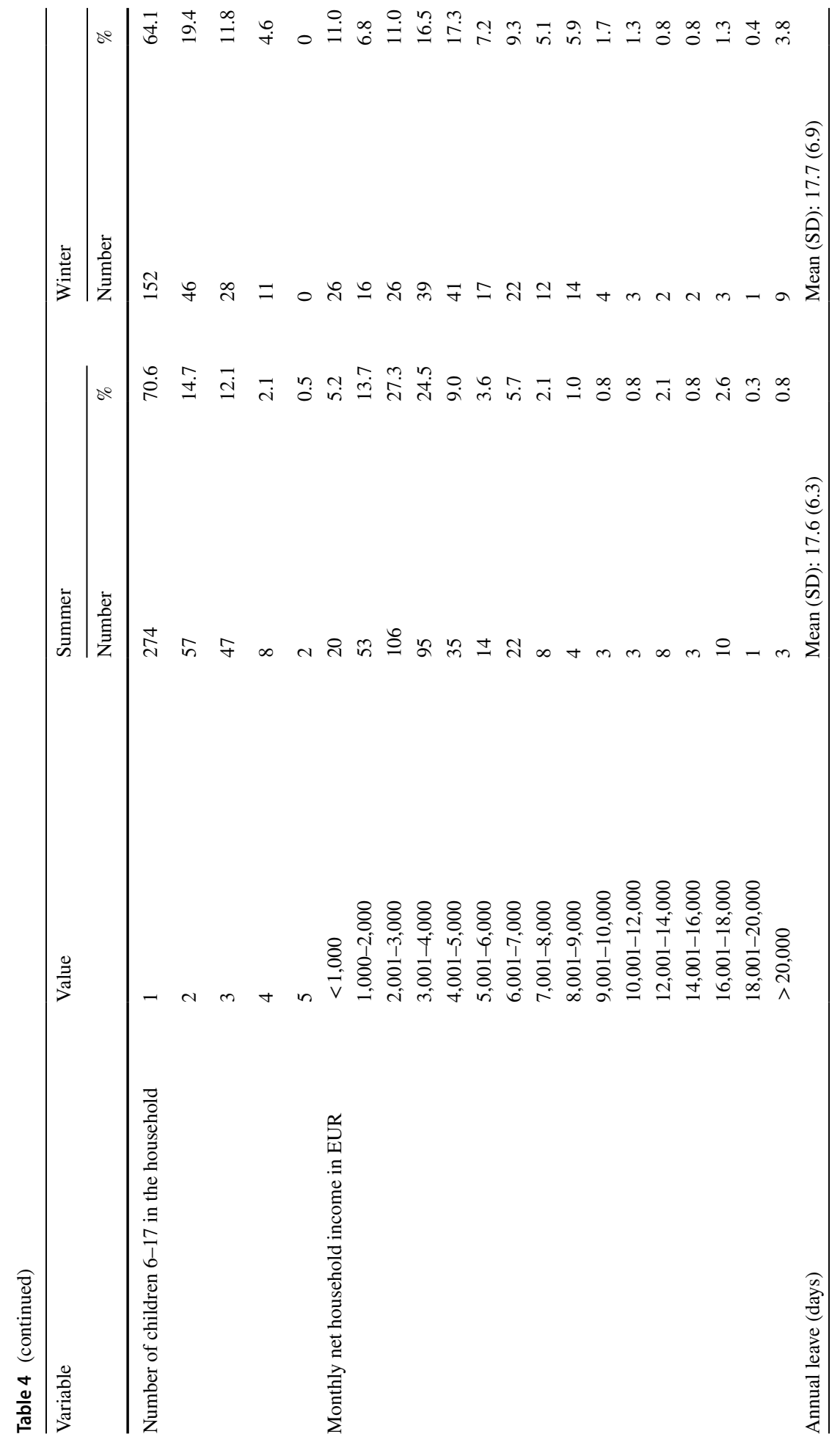




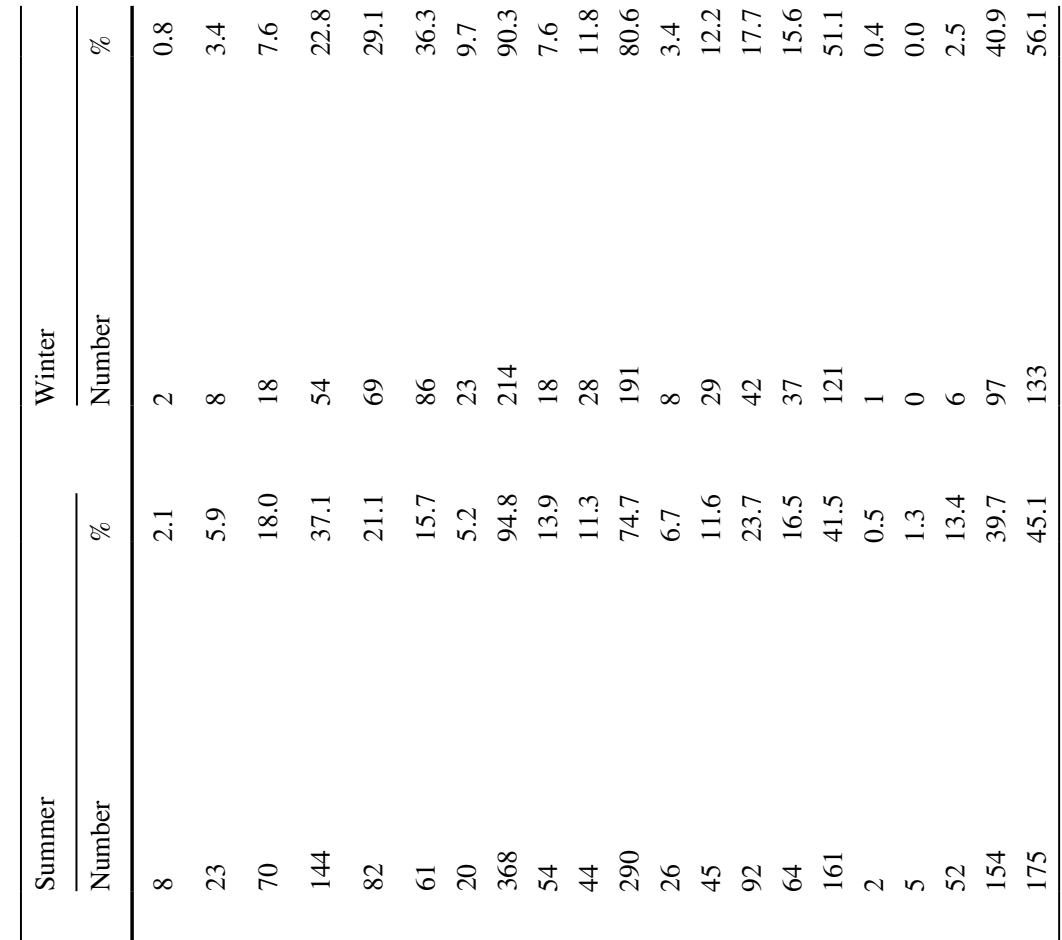

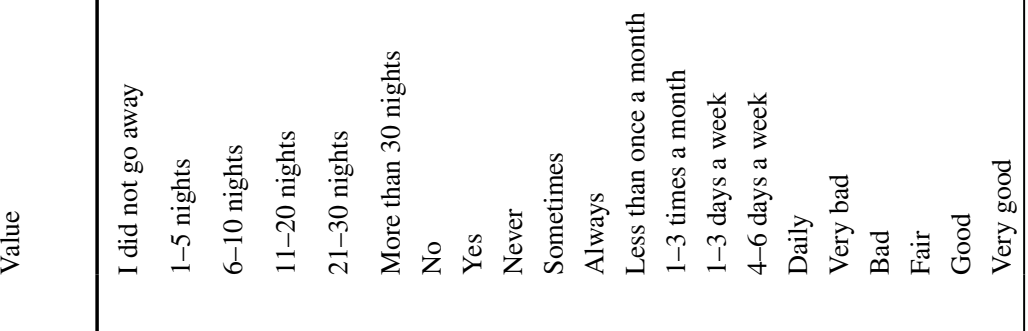

象

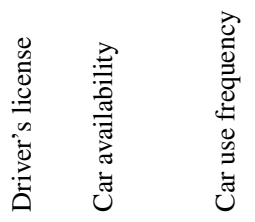

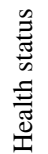




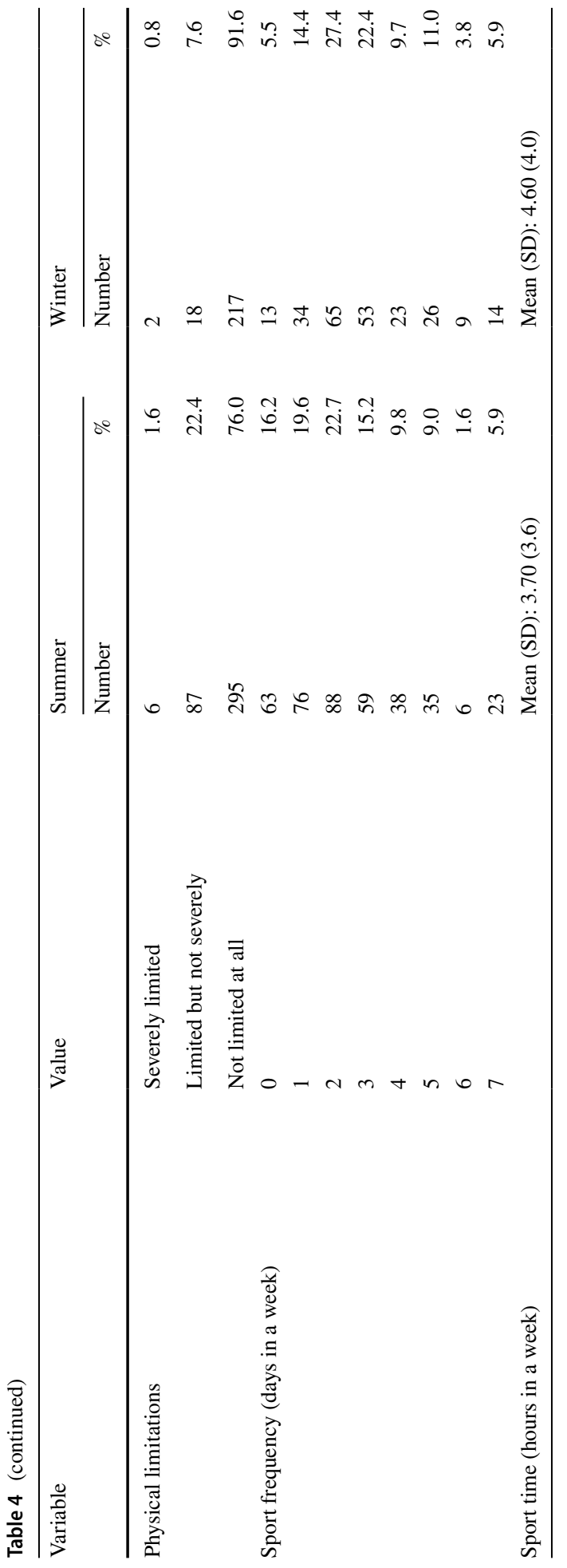




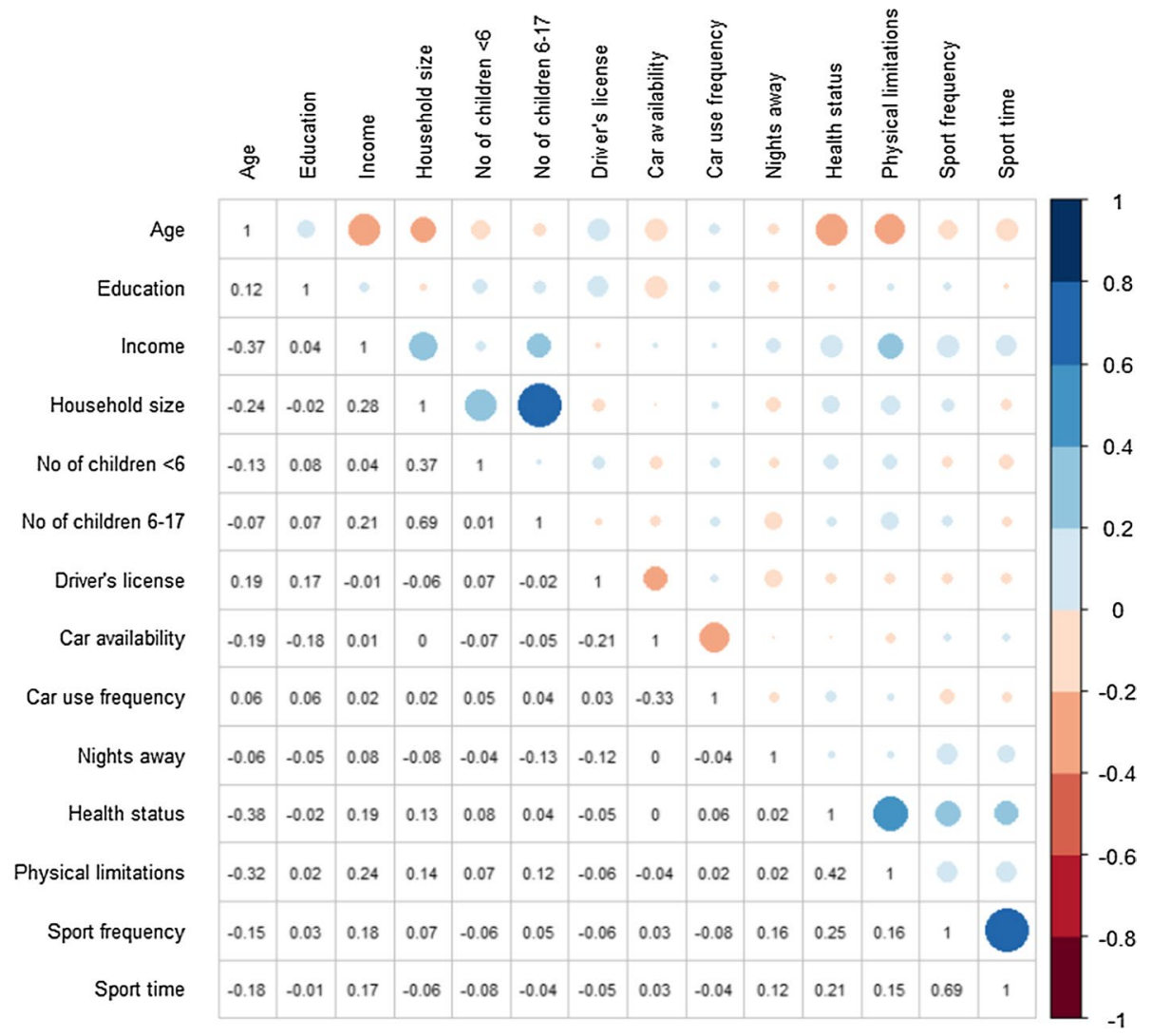

Fig. 4 Correlations of the decision-makers' characteristics

In terms of transport mode used to travel from home to the destination, private car with around $80 \%$ share dominates in both seasons. This is followed by air travel in winter (mostly from the UK thanks to a convenient direct connection from London to Innsbruck) and by train in summer. The major reason for choosing a particular transport mode is convenience (most direct, accessible and flexible mode) in both seasons. In winter, luggage plays an important role, as do price, journey time and distance. In summer, factors other than convenience are far less important. Figure 5 illustrates the relationship between the chosen transport mode and the factors specified as driving this decision. Visitors in both seasons declare to be generally well informed about the journey options. However, only winter tourists state that they are sufficiently informed about the transportation at the destination.

In terms of accommodation types, summer tourists definitely prefer hotels (65\%) to guesthouses (19\%), apartments and campsites (Table 6). Winter tourists lean towards hotels (44\%), but also choose guesthouses relatively often (35\%). Average prices (per person per night) are, even despite a higher share of guesthouse stays in the sample, about 15 EUR higher in winter than in summer, which clearly implies that winter is the more expensive season. 


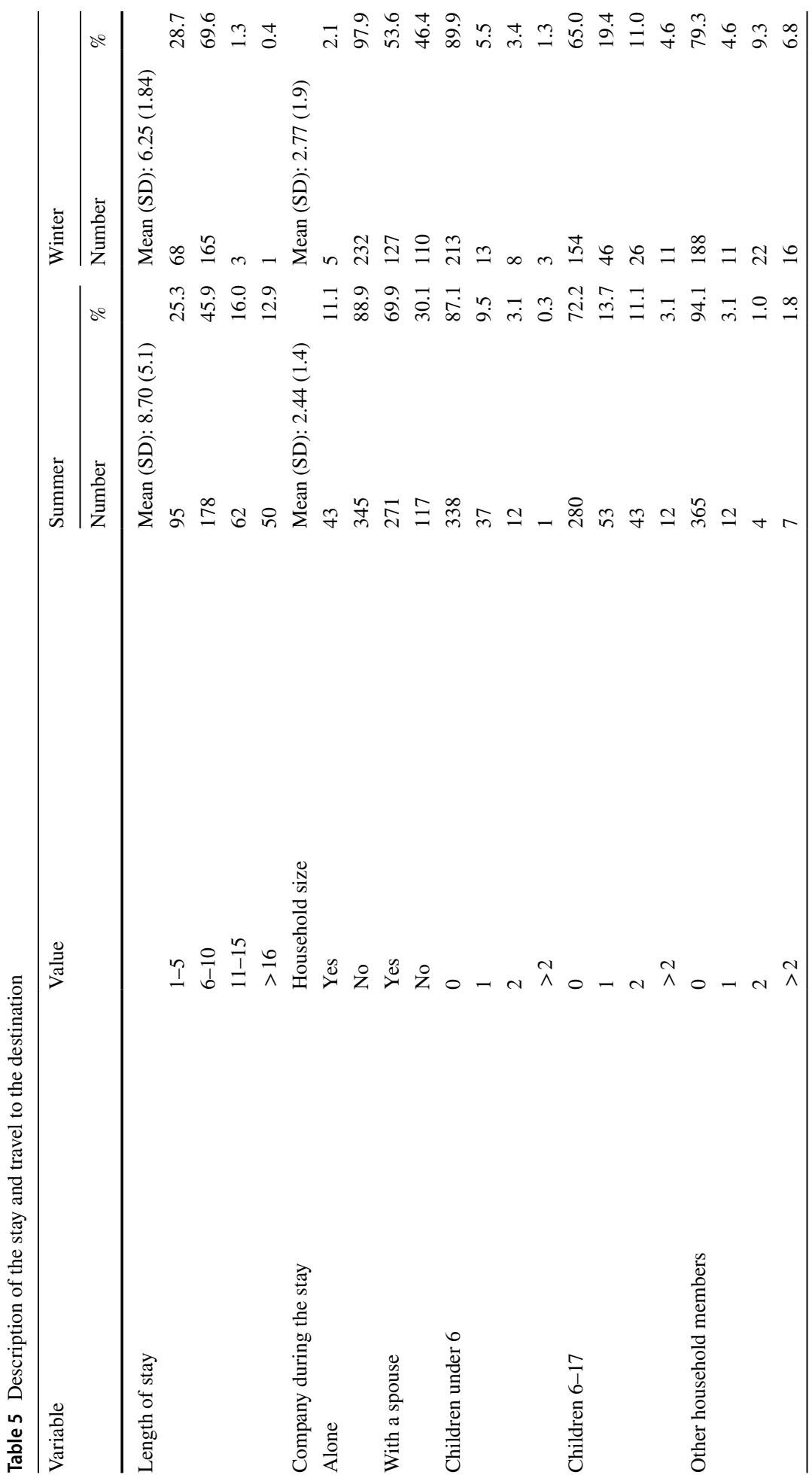




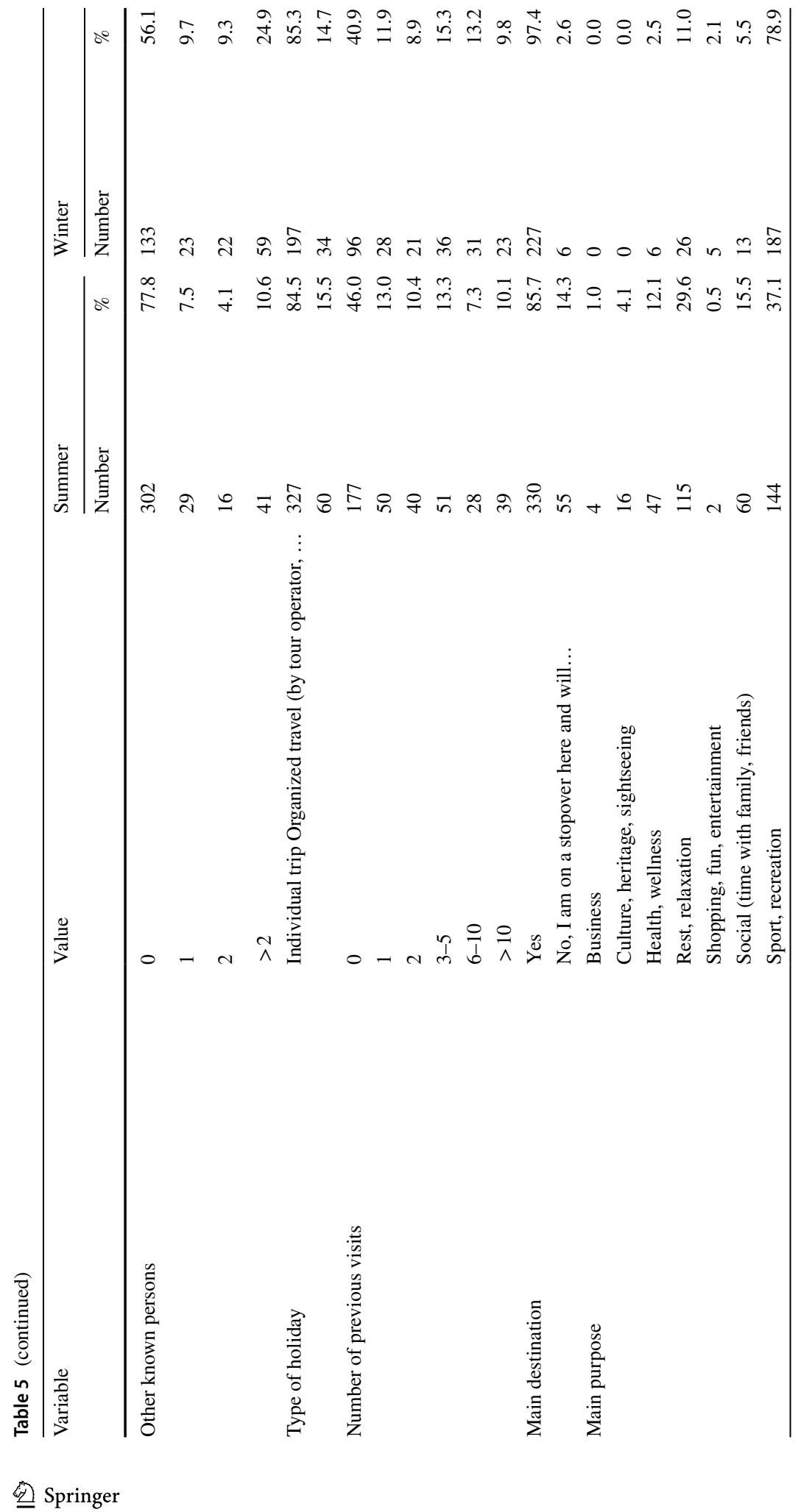




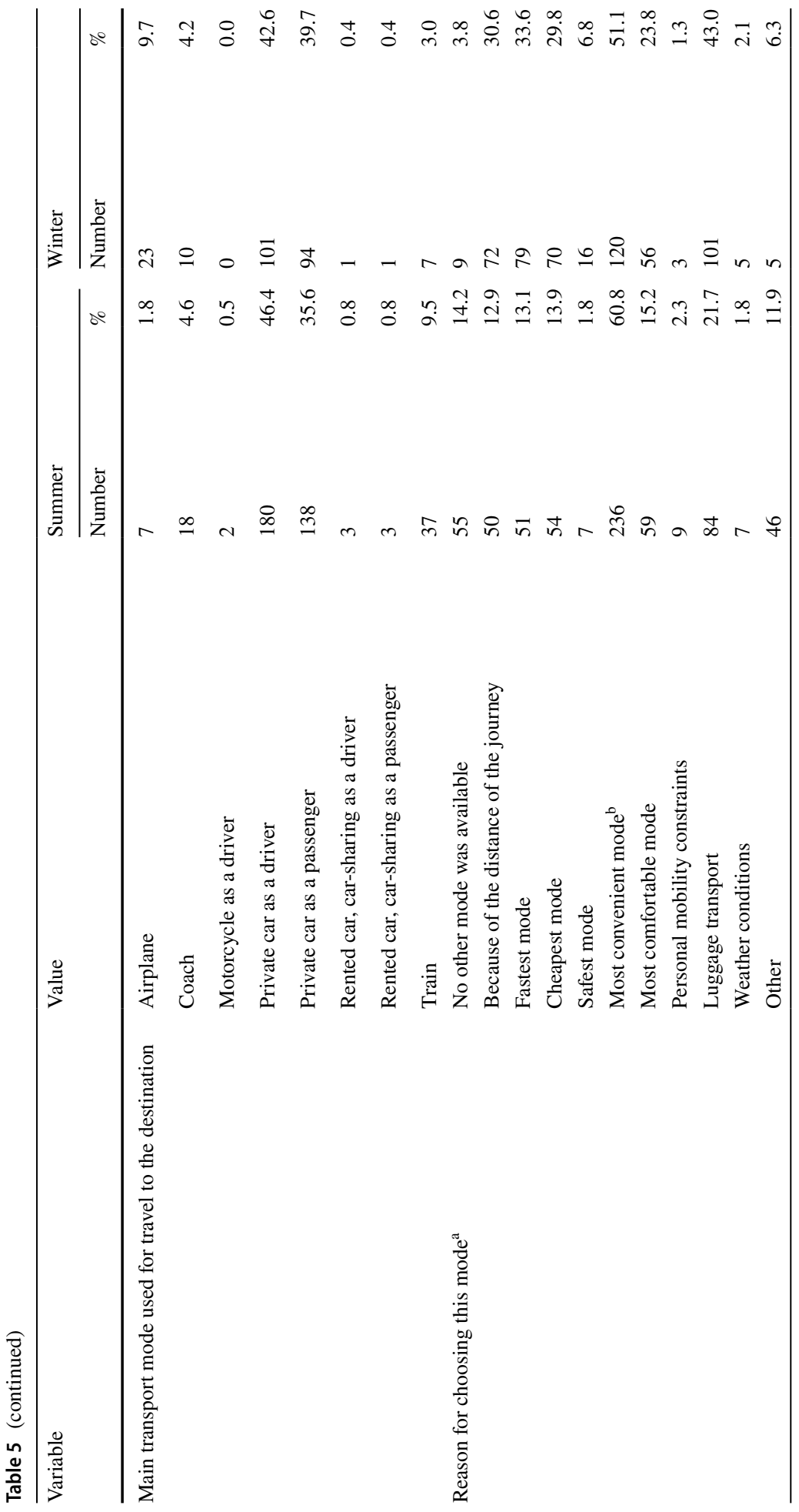




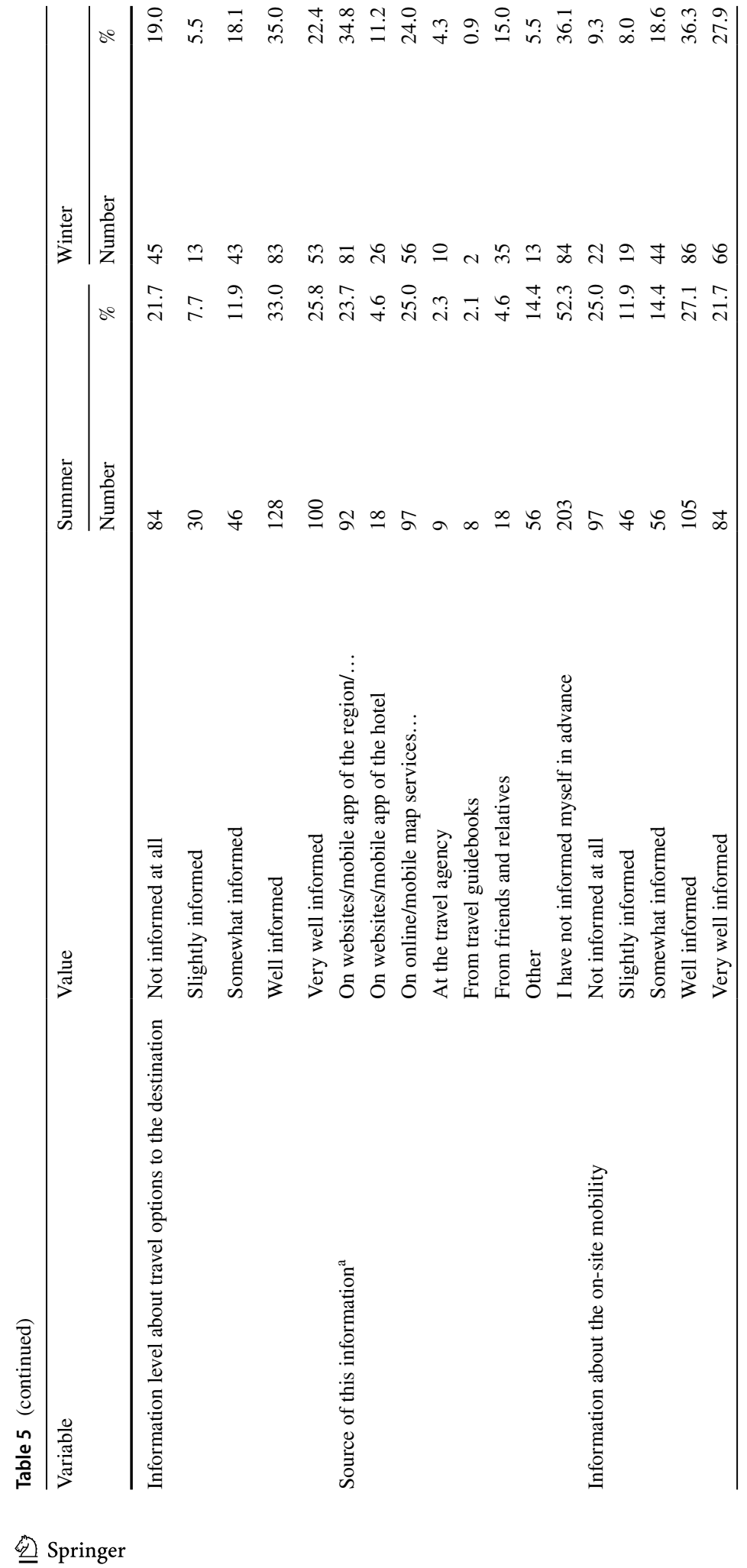




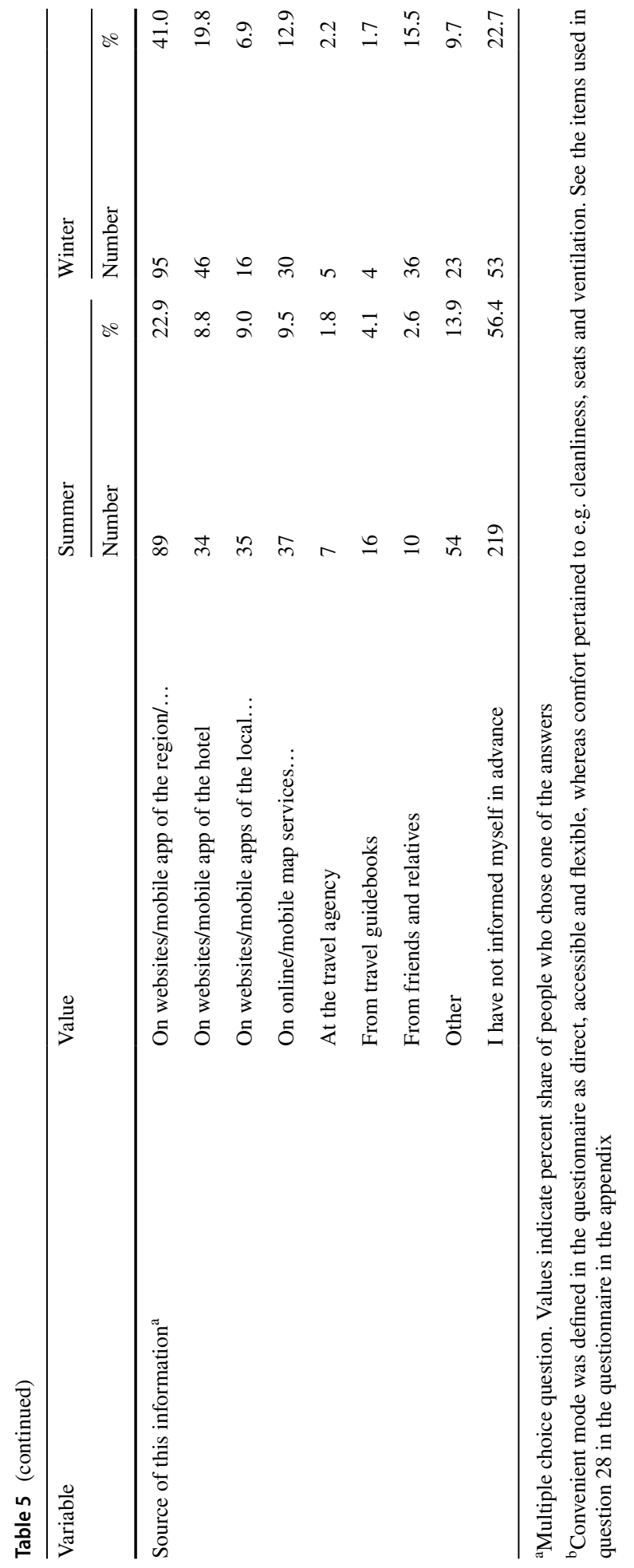




\section{Summer}

Airplane

Coach

Motorcycle as a driver

Private car as a driver

Private car as a passenger

Rented car, car-sharing as a driver

Rented car, car-sharing as a passenger

Train

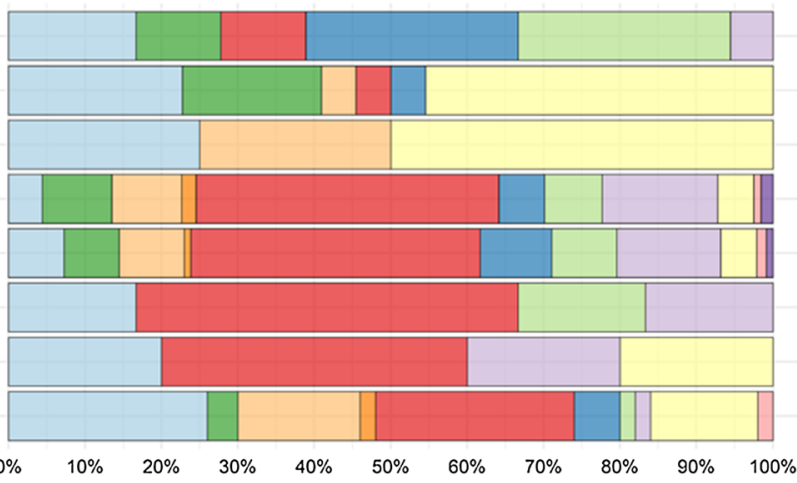

Winter

Airplane

Coach

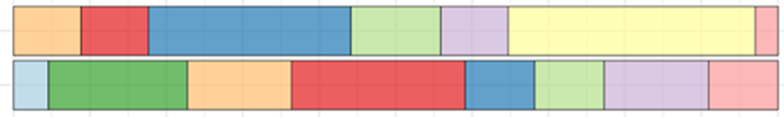

Motorcycle as a driver

Private car as a driver

Private car as a passenger

Rented car, car-sharing as a driver

Rented car, car-sharing as a passenger

Train

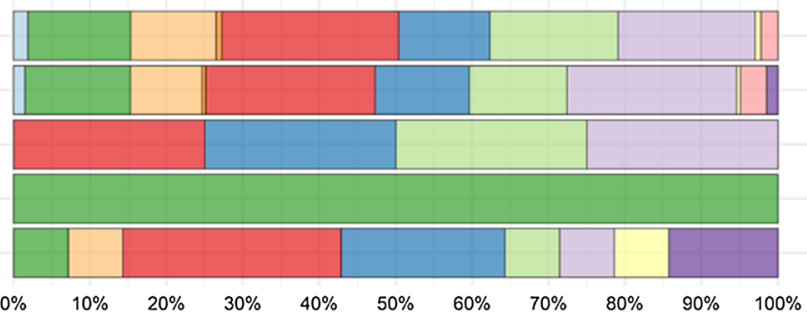

No other mode was available

Because of the distance of the journey

Fastest mode

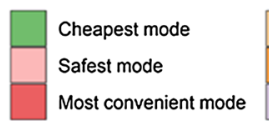

\begin{tabular}{l}
$\square$ Most comfortable mode \\
Personal mobility constraints \\
\hline
\end{tabular}

Weather conditions Other

Fig. 5 Reasons for choosing particular transport mode for travel to the destination (multiple choice possible)

\section{Activities}

Figure 6 presents locations of the accommodations where the respondents stayed.

Figure 7 illustrates activity locations (i.e. trip start points). The area overlaps to a large extent with Fig. 6, which means that activities are performed predominantly within the valley, in the vicinity of the place of stay. Tourists make excursions outside their region relatively rarely. The locations of activities are very concentrated in winter and are close to the main road axis and ski resorts, whereas in summer they are more uniformly distributed across the regions and are more distant from the center of the regions. Visits to places outside the valleys, such as picturesque lakes (Achensee) or cities with tourist attractions (Innsbruck, Schwaz, Kufstein) were reported more frequently in summer than in winter. 
Table 6 Characteristics of the accommodations reported in the survey

\begin{tabular}{|c|c|c|c|c|c|}
\hline \multirow[t]{2}{*}{ Variable } & \multirow[t]{2}{*}{ Value } & \multicolumn{2}{|l|}{ Summer } & \multicolumn{2}{|l|}{ Winter } \\
\hline & & Number & $\%$ & Number & $\%$ \\
\hline \multirow[t]{4}{*}{ Type of accommodation } & Apartment & 42 & 10.8 & 49 & 20.7 \\
\hline & Camping & 19 & 4.9 & 3 & 1.3 \\
\hline & Hotel & 252 & 65.0 & 103 & 43.5 \\
\hline & Guesthouse & 75 & 19.3 & 82 & 34.6 \\
\hline \multirow[t]{5}{*}{ Standard(number of stars) ${ }^{\mathrm{a}}$} & 2 & 2 & 0.8 & 0 & 0 \\
\hline & 3 & 50 & 19.8 & 15 & 14.6 \\
\hline & 4 & 165 & 65.5 & 72 & 69.9 \\
\hline & 4.5 & 35 & 13.9 & 13 & 12.6 \\
\hline & 5 & 0 & 0 & 3 & 2.9 \\
\hline Price per person per night [EUR] & & \multicolumn{2}{|c|}{ Mean (SD): 68.4 (32.9) } & \multicolumn{2}{|c|}{$\begin{array}{l}\text { Mean (SD): } 82.3 \\
\quad(39.3)\end{array}$} \\
\hline
\end{tabular}

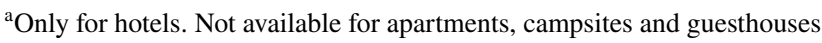
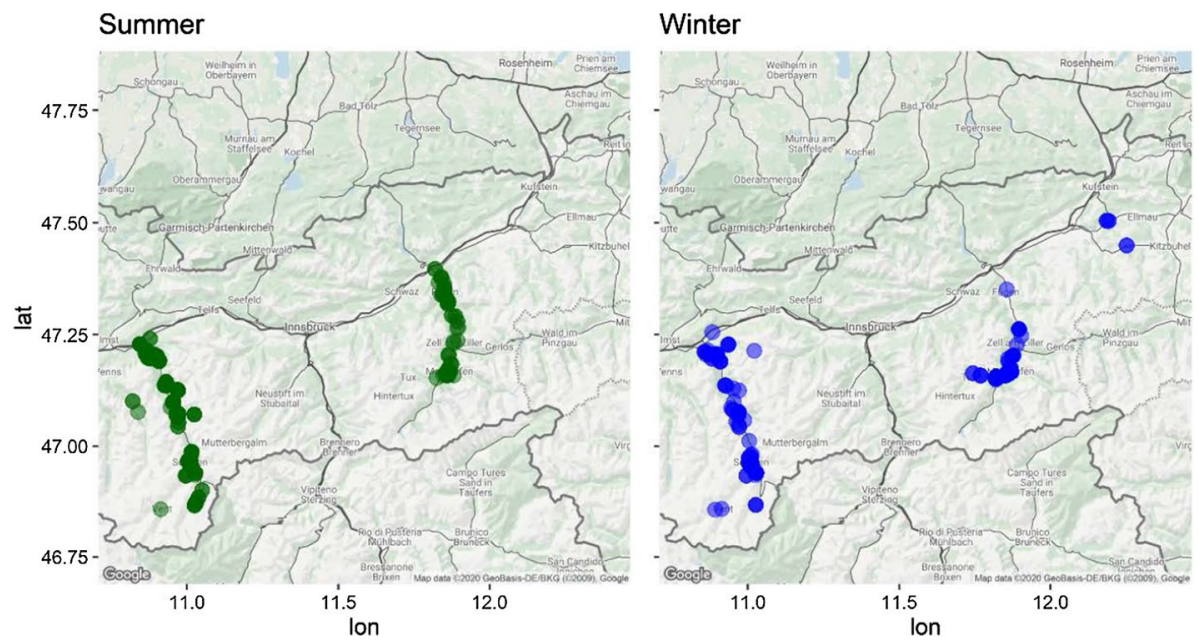

Fig. 6 Locations of the accommodations reported in the survey

\section{Mobility rates}

The general level of mobility of tourists at the destination can be described by number of trips, kilometers traveled and time spent on travel. The average number of trips per person per day in the sample is 2.5 (Table 7). Compared to the values generated by the residents of Tyrol, tourists appear to be less mobile. The difference becomes even more apparent when compared to mobility rates of residents in municipalities with intensive tourism, who make 3.8 trips per day (Köll and Bader 2011). Similarly, in comparison with mobility levels measured in countries where the visitors come from, mobility levels during vacation 

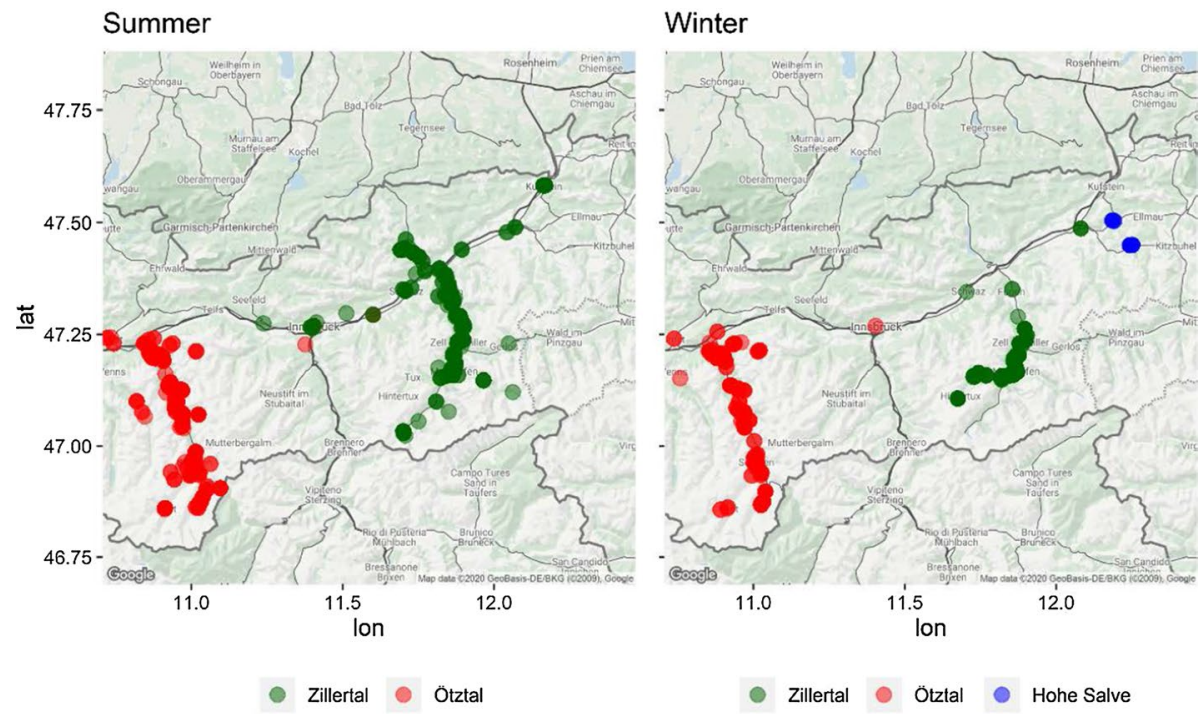

Fig. 7 Location of the activities depending on survey location

are also trending lower (except for the $\mathrm{UK}^{3}$ (NatCen Social Research 2019)). This implies that people are generally less mobile during their out-of-home stays than on a typical day at home. However, one should point out regional variations within these countries and methodological differences between the studies before generalizing the results.

In terms of distance traveled, tourist cover substantially fewer kilometers per day on vacation than on an average day at home. However, there are large country-dependent differences, with Austrians traveling the shortest and Germans the longest distances. In terms of time spent on travel, both the Austrian and foreign tourists achieve significantly lower values during vacation than when at home. Only German visitors stand out, spending on average $75 \mathrm{~min}$ per day compared to $80 \mathrm{~min}$ in their daily behavior.

\section{Transport mode choice of the respondents}

The descriptive analysis of tourists' choices in this paper is limited to transport mode choice. In summer, the share of trips made by car in the sample hits the highest value of almost $50 \%$, followed by walking with $40 \%$, transit (9\%) and cycling (1\%). In winter, walking is the dominating mode reaching $47 \%$, followed by driving and transit, with $36 \%$ and $17 \%$ respectively. Cycling was not reported in winter.

Figures 8 and 9 provide informative insights into the relationship between transport mode choice and sociodemographic and stay-related variables. For instance, tourists over 65 years old choose transit more often than other age groups, especially in winter. Those who frequently use cars at home are also more likely to choose cars on vacation (in summer). Interestingly, good health and lack of physical disabilities results in more walking trips in winter, but less in summer.

\footnotetext{
${ }^{3}$ There are no fully comparable data on trips rates available for the UK—only for England.
} 
Table 7 Mobility rates of the surveyed sample of tourists and the corresponding rates in countries where the majority of guests in Tyrol originates from. Values per day per person (mobile and non-mobile persons together)

\begin{tabular}{|c|c|c|c|}
\hline Study population & Daily distance $[\mathrm{km}]$ & Daily travel time [min] & No of trips per day ${ }^{a}$ \\
\hline Tourists - total & $23.2(28.8 / 14.2)^{\mathrm{b}}$ & $59(72 / 39)^{\mathrm{b}}$ & $2.5(2.4 / 2.7)^{\mathrm{b}}$ \\
\hline Tourists from AT & 11.3 & 22 & 2.1 \\
\hline Tourists from DE & 27.2 & 75 & 2.6 \\
\hline Tourists from NL & 16.4 & 38 & 2.7 \\
\hline Tourists from $\mathrm{CH}$ & 22.3 & 45 & 2.2 \\
\hline Tourists from UK & 21.1 & 26 & 2.9 \\
\hline Residents in AT $(2013 / 2014)^{\mathrm{c}}$ & 36 & 68 & 2.6 \\
\hline Residents in AT, Tyrol $(2013 / 2014)^{\mathrm{c}}$ & 35 & 69 & 2.7 \\
\hline Residents in AT, Tyrol (2011) ${ }^{\mathrm{d}}$ & - & - & 4.1 \\
\hline $\begin{array}{l}\text { Residents in AT, Tyrol (intensive } \\
\text { tourist municipalities) }(2011)^{\mathrm{d}}\end{array}$ & - & - & 3.8 \\
\hline Residents in DE (2018) ${ }^{\mathrm{e}}$ & 39 & 80 & 3.1 \\
\hline Residents in NL $(2013)^{\mathrm{f}}$ & 35.6 & 65 & 3.1 \\
\hline Residents in CH (2017) $)^{\mathrm{g}}$ & 36.8 & 90.4 & 3.4 \\
\hline Residents in England $(2018)^{\mathrm{h}}$ & 29 & 62 & 2.7 \\
\hline
\end{tabular}

${ }^{a}$ Excluding cable car trips

${ }^{\mathrm{b}}$ Values for summer and winter respectively

${ }^{\mathrm{c}}$ Bundesministerium für Verkehr, Innovation und Technologie (2016)

${ }^{\mathrm{d}}$ Köll and Bader (2011)

${ }^{\mathrm{e}}$ Bundesministerium für Verkehr und digitale Infrastruktur (2018)

${ }^{\mathrm{f}}$ Hoogendoorn-Lanser et al. (2015)

${ }^{\mathrm{g}}$ Bundesamt für Statistik (BFS) (2017)

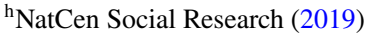

As far as the characteristics of the stay are concerned, one can notice that guests in the Ötztal valley choose car more often than guests in the other two regions. This holds in both seasons. The Zillertal, on the other hand, has the highest percentage of transit users, which can be attributed to a more extensive transit network, including a 32-km-long narrow-gauge railway that runs through the valley. Traveling to the destination by private car leads to a high share of car trips on site. In contrast, train and coach travelers tend to use local public transport relatively frequently. Also, better knowledge of the destination has a favorable effect on choosing transit at the cost of car.

Figure 10 illustrates the temporal distribution of trips during one day (averaged) in summer and winter seasons. In winter, two distinct peaks are apparent for all three modes, which clearly reflects how the mobility patterns are associated with the opening hours of ski resorts. Driving in summer exhibits similar morning and evening peaks as it is in winter, whereas walking trips are more uniformly distributed over the course of a day. In summer, unlike in winter, afternoon return trips on transit are spread over several hours and do not form a peak as they do in the morning.

Figure 11 presents the modal split with respect to the trip purpose. A distinct pattern can be observed, in particular in summer, in mode choice preferences between for traveling to social activities (e.g. going out, restaurant visit) and traveling to outdoor 
and sport activities. In the first case, walking is the dominant mode, whereas in the latter, and generally with the increasing need to transport any kind of luggage or specific items (trekking poles, climbing or water sports equipment, etc.), the share of car trips escalates. An exception to this rule is skiing, where a relatively high proportion of transit trips can be explained by the high-quality ski-bus services offered in winter, tailored specifically to skiers' and snowboarders' needs.

Figures 12 and 13 illustrate how long the trips undertaken by tourists are by each mode (data at the level of individual observations, not respondents). Tourists in summer travel longer distances and spend more time traveling than in winter, regardless of which transport mode they choose (see also Table 7).

\section{Joint travel}

Joint travel accounts for a very high share of all trips in the sample. Out of 3120 trips, 3048 trips $(98 \%)$ were made with an accompanying person (not necessarily a relative or household member), 2671 trips (86\%) with at least one household member (this includes e.g. grandparents living with the family), whereas 2594 trips (83\%) were made with immediate family members, i.e. a spouse or children.

Figure 14 illustrates the relationship between the chosen mode and the family composition on a trip, as well as between the chosen mode and the number of accompanying household members. In principle, as the group size increases, the preference for walking decreases and instead the preference for driving increases.

Figure 15 illustrates the relationship between trip distance and family composition. As long as traveling with children clearly influences the choice of transport mode, it does not seem to influence the choice of destination much. Parents with and without children, alone and with spouses, undertake longer trips equally often. Apparently, parents do not avoid traveling with kids to distant locations within the vacation region. They adapt the mode choice in the first place, but the final destination choice remains unaffected. ${ }^{4}$

\section{Impact of weather}

Respondents were asked to assess the impact of weather on their activity and transport mode choices. In $5.92 \%$ cases in summer and $1.52 \%$ cases in winter, they were forced to choose an alternative activity, whereas only in $0.98 \%$ cases in summer and $1.8 \%$ cases in winter, they had to resort to another means of transport due to unfavorable weather conditions. These statements show a very low impact of weather on tourists' choices and suggest that tourists are determined to follow the vacation schedule (that they probably diligently prepared beforehand) no matter the weather.

If we combine the responses based on personal weather perception with real measurement data from weather stations located near the starting points of the trips, a similar picture emerges (Table 8). Only in up to $5 \%$ observations, when it rained in summer, respondents declared to have chosen another transport mode than planned.

This is confirmed in Fig. 16 illustrating the transport mode choice as a function of precipitation. Visitors seem to be very indifferent to precipitation-in fact, the share of trips made on foot is higher on rainy days in summer and snowy days in winter than on

\footnotetext{
4 It might however result from a small number of destinations for pursuing the planned activities, forcing families to travel far (e.g. only one ski resort nearby).
} 


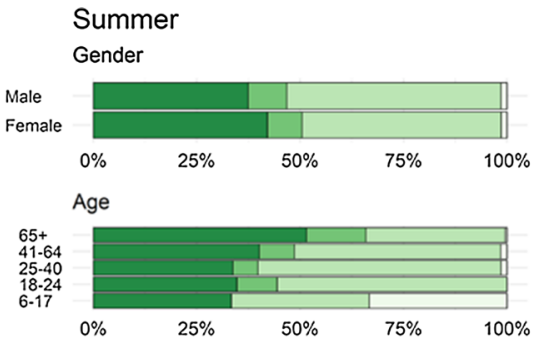

\section{Winter}
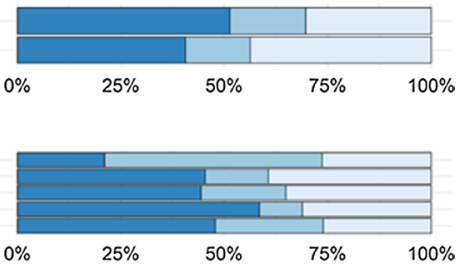

\section{Education}
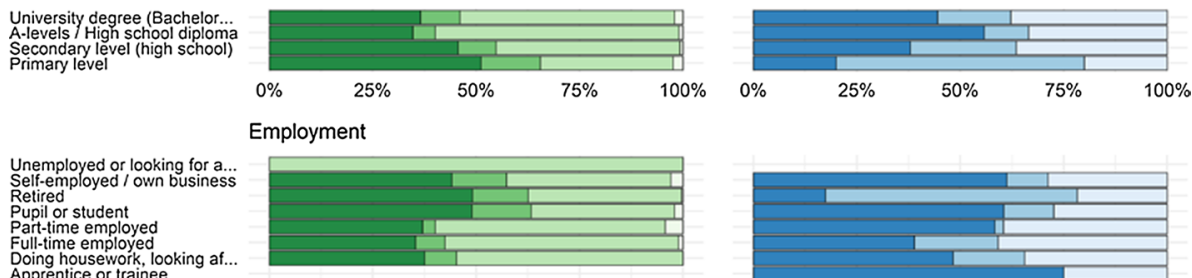

\section{Employment}
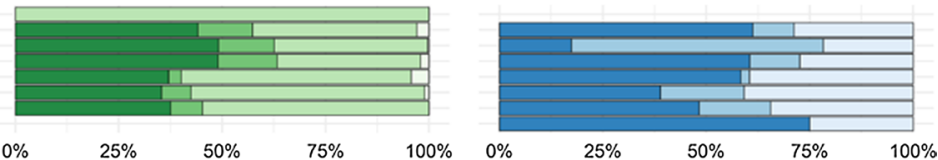

Driver's license
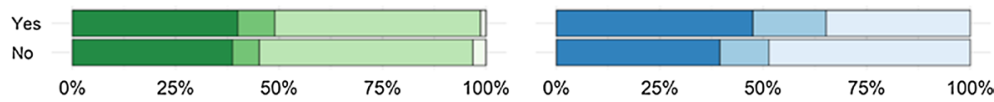

Car availability
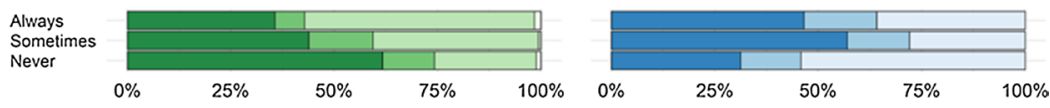

Car use frequency
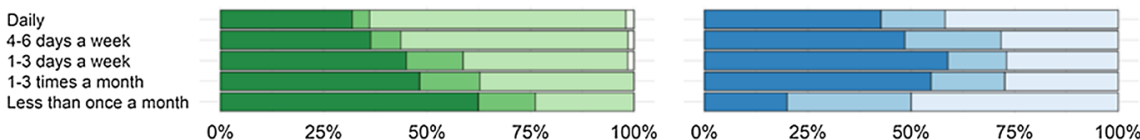

Nights away
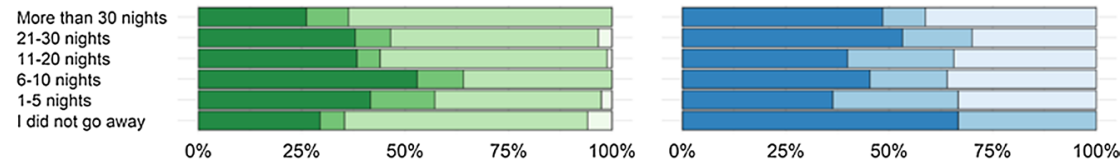

Health status
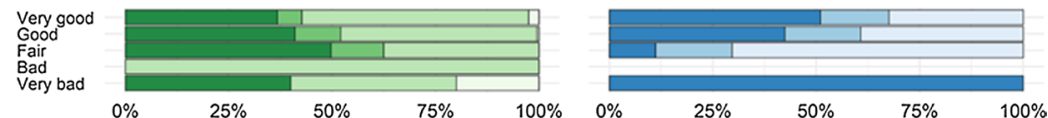

Physical limitations
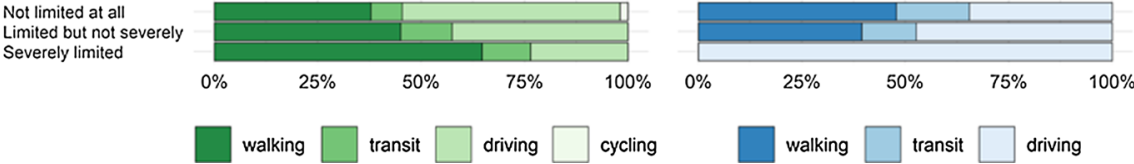

Fig. 8 Chosen mode depending on the sociodemographic characteristics 


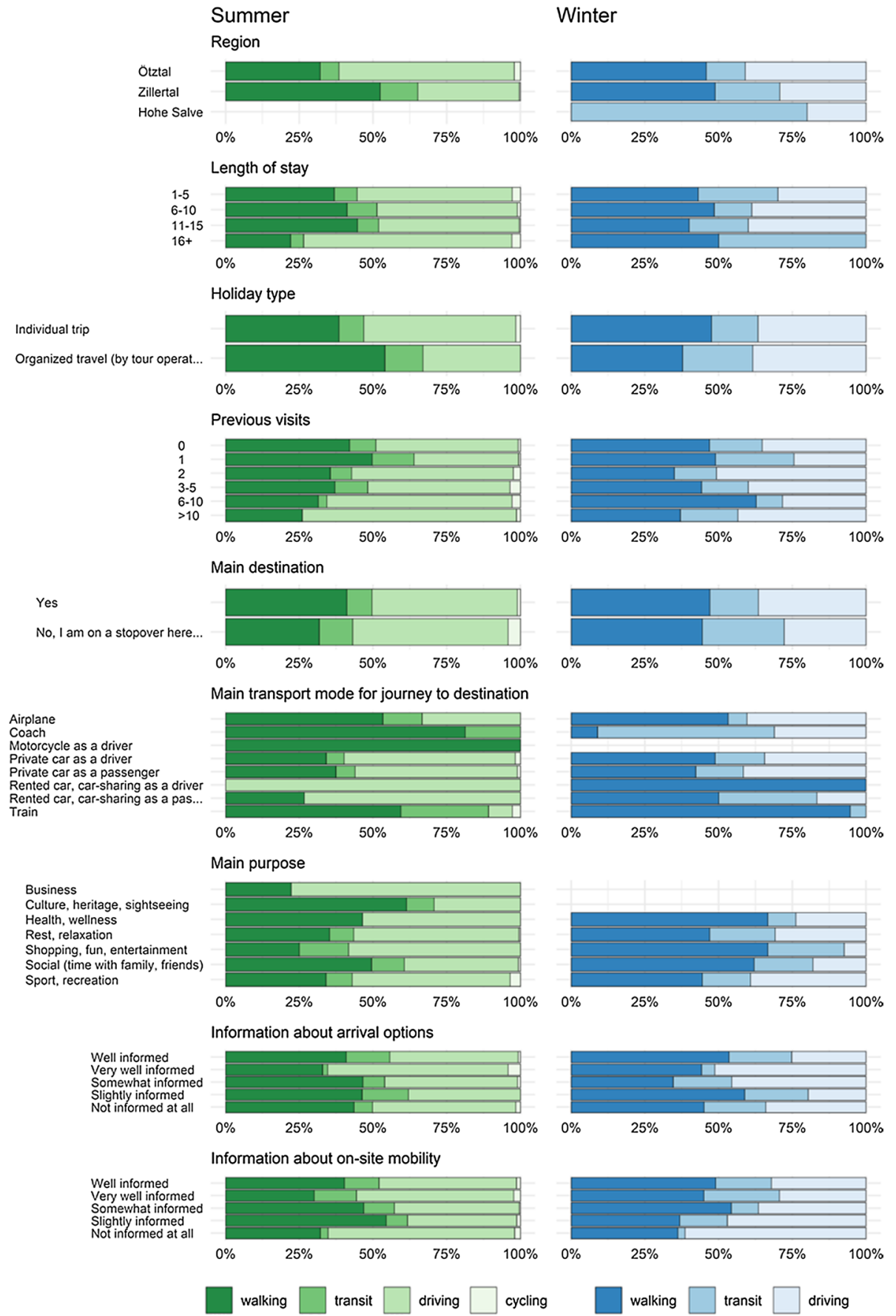

Fig. 9 Chosen mode depending on characteristics of the stay and travel to the destination 
Summer

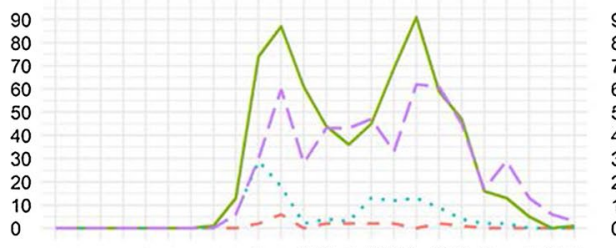

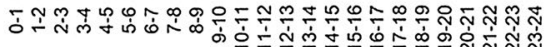

Winter

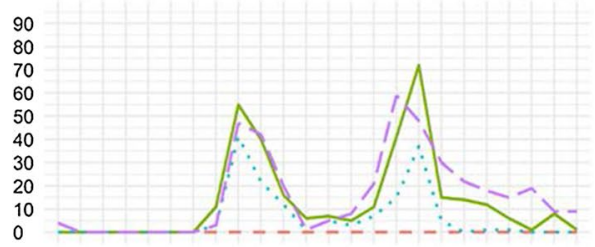

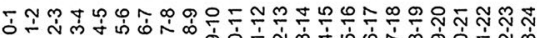
ó

$$
\text { - cycling - driving } \cdots \text { transit }- \text { walking }
$$

Fig. 10 Number of trips made by a given mode depending on time of day

\section{Summer}

Skiing/snowboarding

Rental service

Going out, social

Restaurant

Shopping (daily needs)

Walking

Hotel

Hotel - after last trip

Hiking/trekking

Shopping, fun, entertainment

Culture, sightseeing

Relaxation, spa

Cycling/MTB

Climbing

Other sports

Visits

Drop off/pick up

Water sports

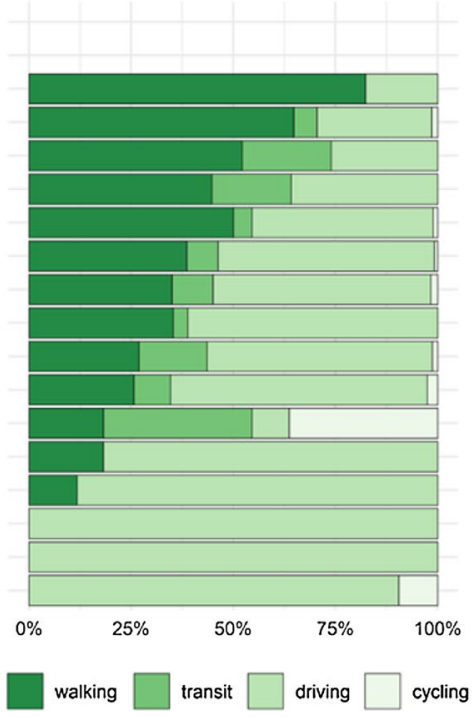

Winter
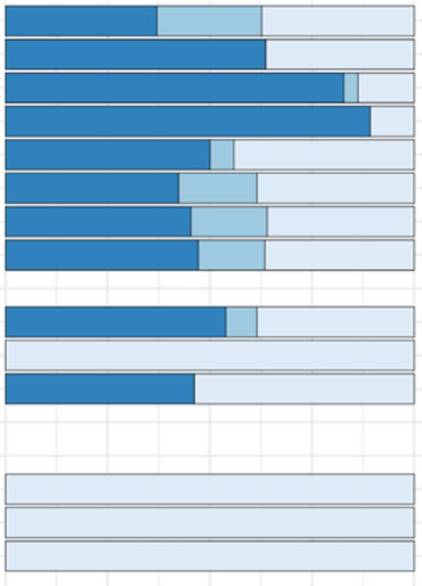

$0 \%$

$25 \%$

$75 \% \quad 100 \%$

walking driving

Fig. 11 Chosen mode depending on current trip purpose (i.e. the activity following the current trip)

days with no precipitation. This positive effect on walking raises doubts about the plausibility of this outcome (however a similar finding was reported also by Saneinejad et al. (2012)). It is postulated that studying the activity, destination and mode choice jointly may explain the underlying dependencies more precisely. Not accounting for interference of weather on the activity and destination choice, can lead to questionable results at the mode choice level—an issue also raised by Liu et al. (2015). 


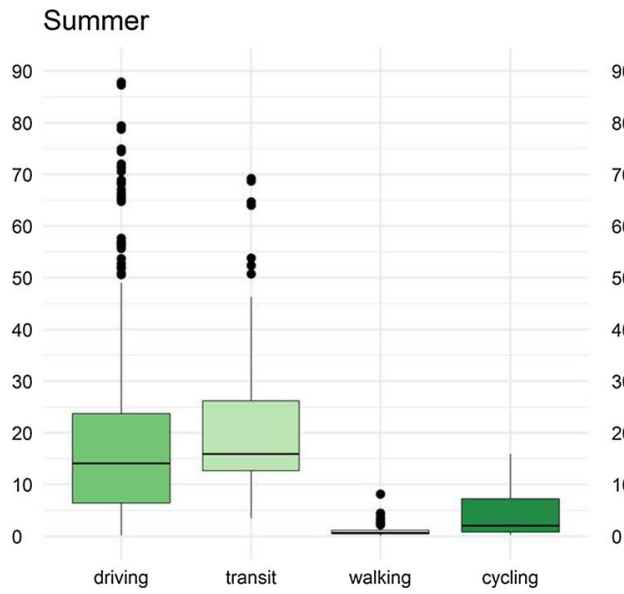

\section{Winter}

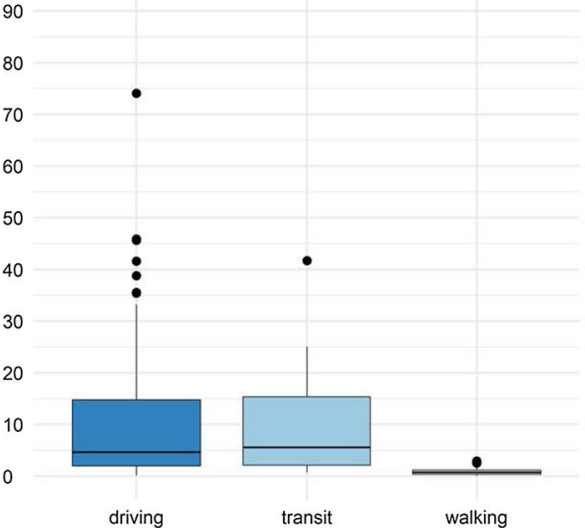

Fig. 12 Length of trips $[\mathrm{km}]$ depending on chosen mode

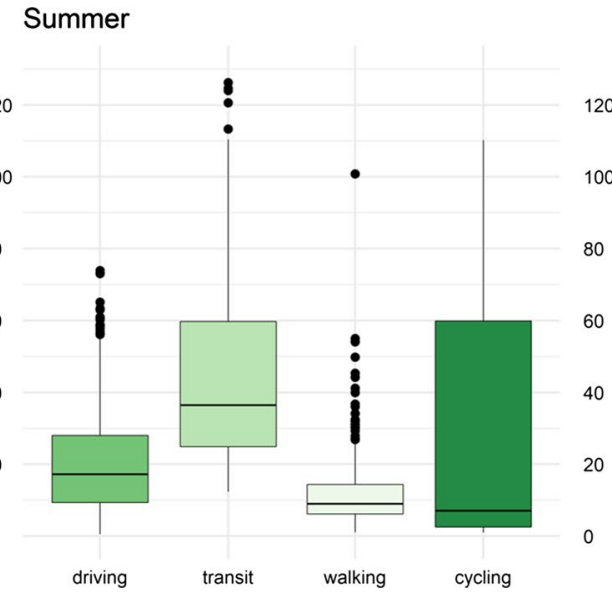

\section{Winter}

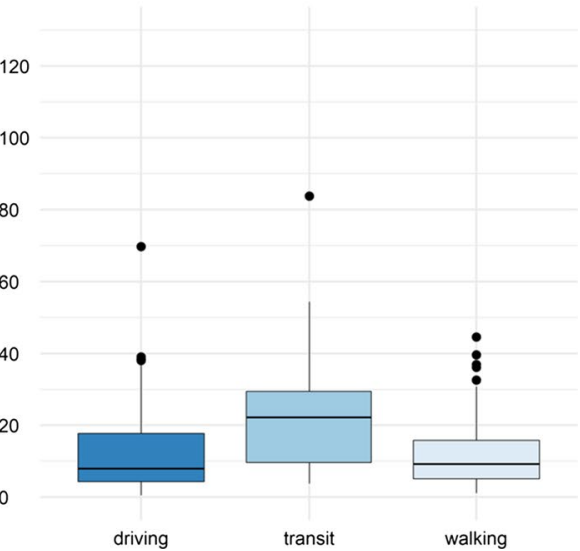

Fig. 13 Duration of trips [min] depending on chosen mode

\section{Conclusion}

The paper reports on the motivation for, design and administration of a data collection effort on tourists' travel behavior at vacation destinations, as well as on basic descriptive results from the sample collected. Given the rising leisure mobility of modern societies (Larsen et al. 2006), there is a growing demand for understanding people's travel behavior in discretionary travel and mobility at non-home locations. This study responds to that demand and contributes to the development of quantitative research on the transport behavior of tourists at the same level as that of residents. The presented dataset is unique in that it describes tourists' actual observed behavior (revealed preferences) at a disaggregate level rather than behavioral intentions (stated preferences), making it a solid basis for developing 


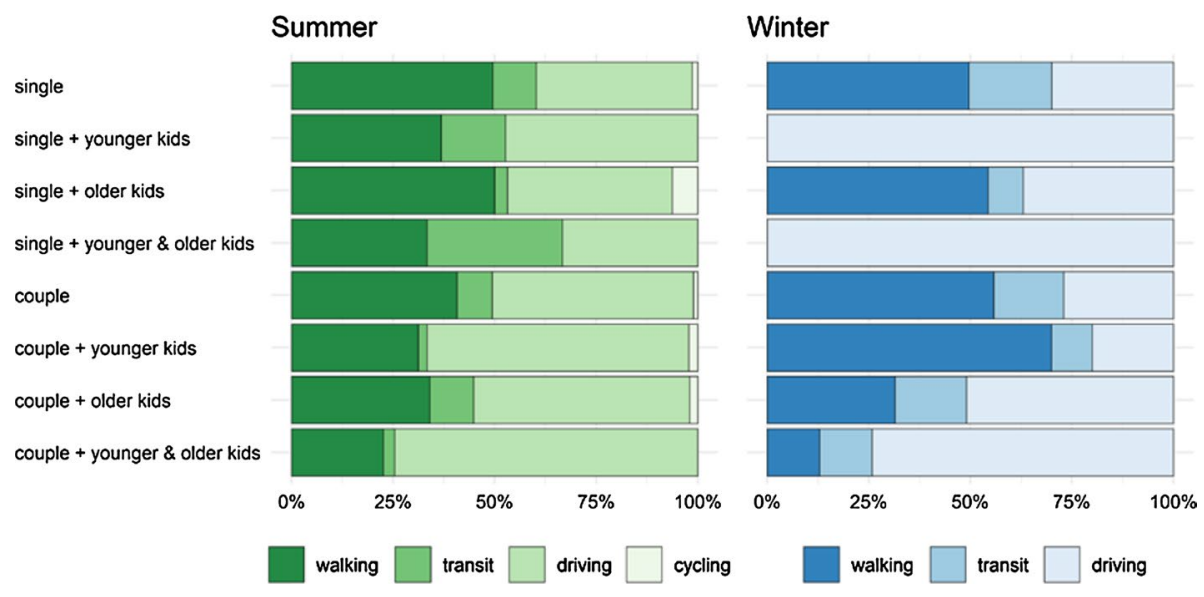

Fig. 14 Chosen mode depending on family composition during the trip

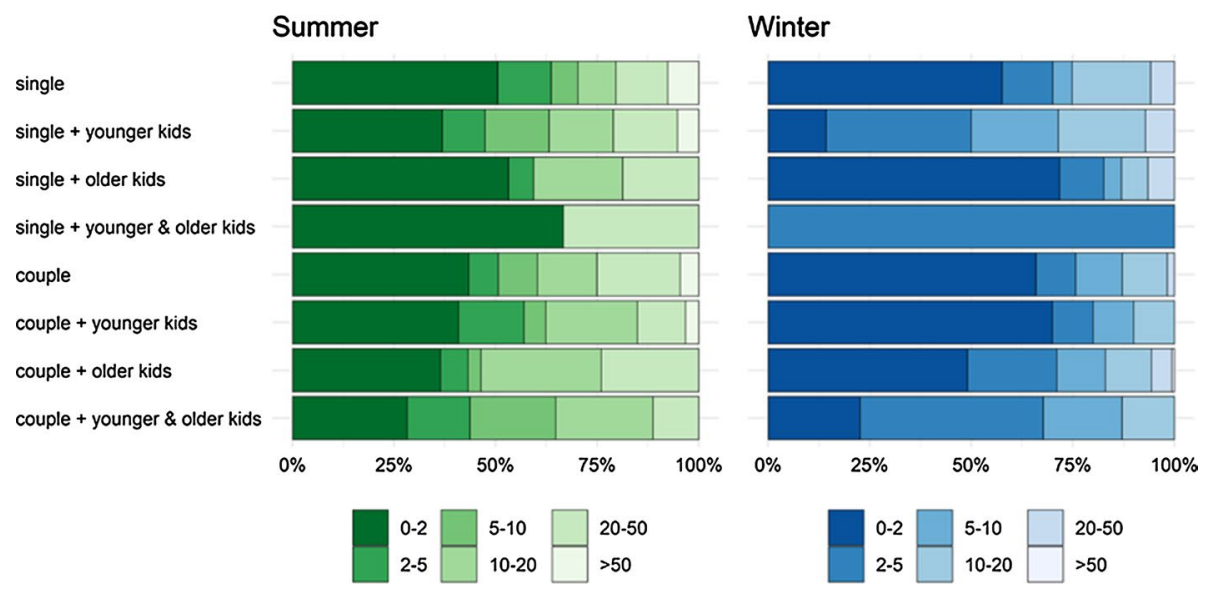

Fig. 15 Distance traveled depending on family composition

behavioral choice models, as is typically done for local residents for which census and national travel survey data are available. This paper provides researchers, transport planners and policy-makers with a groundwork for further analytical and modeling work on tourist travel behavior and should ultimately foster better design of transport policies in tourist regions.

The data collection process builds to some extent on the design of established surveys of everyday travel behavior. However, it is applied in a novel context and to an unconventional population of tourist visitors staying for a short time at a destination for vacation purposes. We postulate that surveys of tourist travel behavior should collect disaggregate data on trips and activities of single respondents using a diary-based approach, if possible accompanied by GPS tracking, and should account for additional variables, beyond travel time, travel cost and level of service, which are typical predictors of home- and workrelated travel choices (Frank et al. 2007). The survey instrument must allow the analyst to precisely differentiate between activities involving movement (e.g. cycling for pleasure) 
Table 8 Impact of (perceived) weather on mode choice

\begin{tabular}{|c|c|c|c|c|c|}
\hline \multirow[t]{2}{*}{ Variable } & \multirow[t]{2}{*}{ Value } & \multicolumn{2}{|l|}{ Summer } & \multicolumn{2}{|l|}{ Winter } \\
\hline & & Precip. $>0$ & Precip. $=0$ & Precip. $>0$ & Precip. $=0$ \\
\hline \multirow[t]{2}{*}{ Impact of weather on mode choice } & $\begin{array}{l}\text { 1st choice } \\
\text { transport } \\
\text { mode (as } \\
\text { planned) }\end{array}$ & $95.1 \%$ & $99.6 \%$ & $100.0 \%$ & $98.0 \%$ \\
\hline & $\begin{array}{l}\text { 2nd choice } \\
\text { transport } \\
\text { mode (plan } \\
\text { B) }\end{array}$ & $4.9 \%$ & $0.4 \%$ & $0.0 \%$ & $2.0 \%$ \\
\hline
\end{tabular}

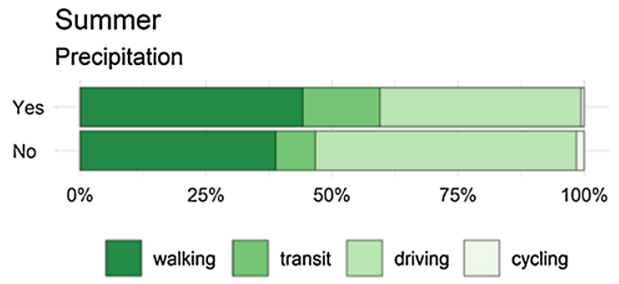

Winter

Fig. 16 Mode choice of tourists depending on precipitation

and movements to activities (e.g. cycling to a supermarket), i.e. displacement to a place where the activity is performed, which can be confusing in a vacation context, where many trips tend to have a strong recreational or sporting character and may serve not only relocation purposes.

We experienced difficulties in establishing effective cooperation with the accommodation providers, both without and with the support of the local DMOs. This affected the choice of the survey methods and, consequently, led to a loss of control over the sampling process (change from distributed PAPI questionnaires to face-to-face CAPI interviews). The study also revealed an ambiguous effect of incentives. Prospective studies should secure a larger budget and test an effect of higher monetary incentives. In particular, a successful implementation of a survey conducted in close cooperation with accommodation providers and accompanied with substantial incentives for the participants and the accommodations would be of value to the scientific community.

The paper also analyzes and compares seasonal differences between mode choice behavior of tourists in summer and winter. The basic descriptive results suggest that the effects of group composition, trip purpose, weather, information about the destination might be of non-negligible magnitude. Thus, although accounting for additional variables leads increases data collection costs, complexity, and response burden, it is strongly advised that this be done as early as at the survey design stage.

The results of a modeling work based on this study revealed several limitations of the dataset. Some specific information that could have contributed to a deeper understanding of tourists' mobility choices was not collected in the survey. These include, in particular, the following: 
- Whether respondents had to carry luggage (e.g. climbing equipment, snow sleds for kids, stroller) on their trip to the activity start location and whether it was bulky and troublesome.

- Whether they brought their own bicycles or e-bikes with them.

- Whether their hotel offered them bicycles or e-bikes for rent or free of charge.

- Whether they purchased any kind of regional guest card in the summer season entitling them to free or discounted use of public transportation.

- The exact age of children (or at least stratified 0-6, 7-15 and 16-20 years) so that it would correspond to single fare categories and allow for more accurate cost calculations.

Sample size is another clear limitation of the study. With 849 respondents, the sample is within the range of comparable studies on tourist mobility. However, it is rather small (approx. 2.5\%) in relation to the average of 34,000 tourists staying in all three regions at any time (given over 85,000 beds available and an average load factor of around $40 \%$ ). It is also not representative, as most of the data was collected using convenience sampling and the response rate to questionnaires distributed in the hotels was very low (which would otherwise have made it possible to control the sampling process). It must be borne in mind that results based on a sample of this kind cannot be easily generalized to larger or different study populations.

As discussed in Sect. Descriptive analysis, a large share of trips within the tourist destination are shorter than $2 \mathrm{~km}$ and are made on foot. The accuracy of distance and travel time calculation for short trips using Google Maps API might become questionable, since factors other than pure walking speed ${ }^{5}$ come into play. Walking speed may, besides personal factors (age, gender, fitness, trip purpose, mood, etc.), depend also on physical conditions such as carried items (sports equipment, baby carriage, groceries), altitude difference, sidewalk surface, or weather conditions (snow layer). This might have implications for prospective choice modeling work, given the considerable share of short walking trips in the current dataset. Future studies should consider collecting even more precise data to account for this.

\section{Appendix}

See Figs. 17, 18, 19, 20.

\footnotetext{
${ }^{5}$ Google does not disclose what speed they use in their routing system. As long as transit is concerned, it is based on timetable; car speeds are based on live traffic data, but the assumptions behind walking and cycling are unknown. However, one can observe that the speed varies depending on the elevation difference.
} 


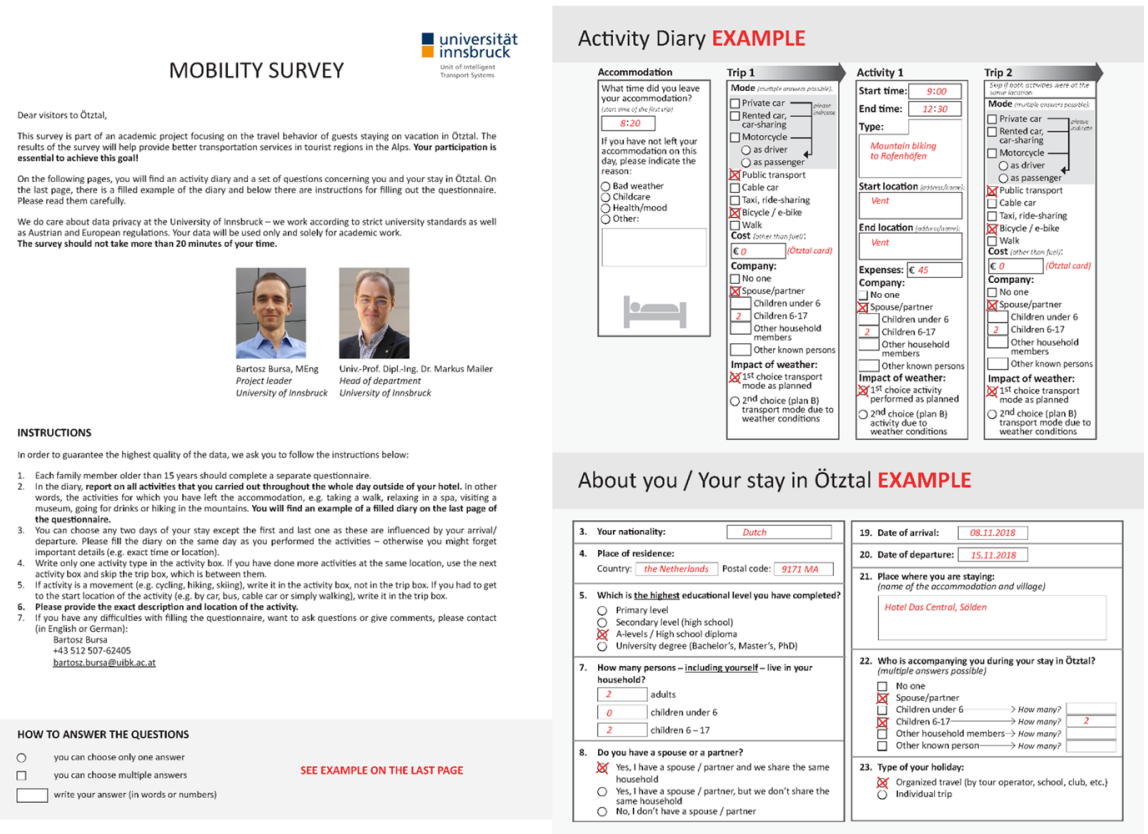

Fig. 17 PAPI questionnaire—front and back cover

About you

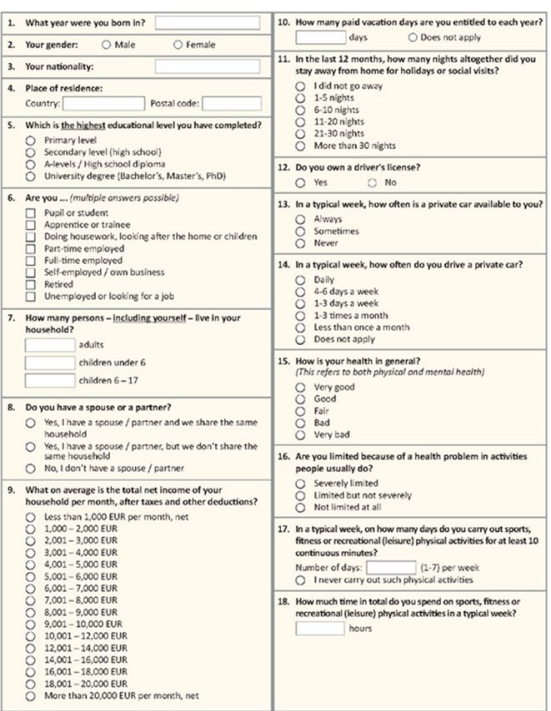

Your stay in Ötztal

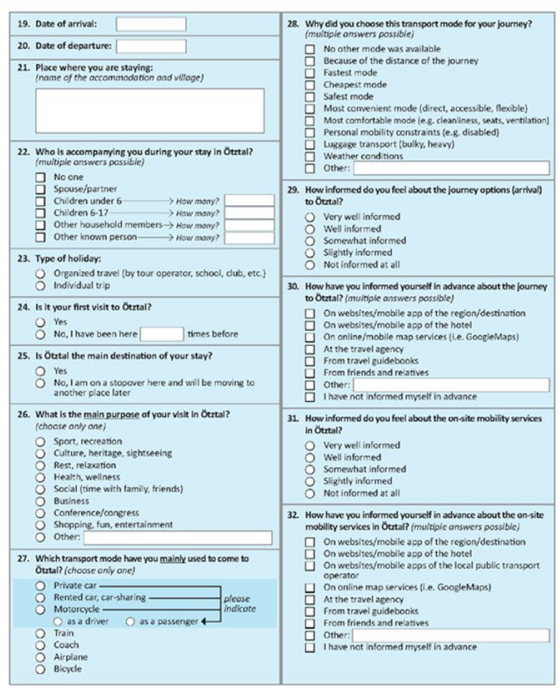

Fig. 18 PAPI questionnaire—page 1 


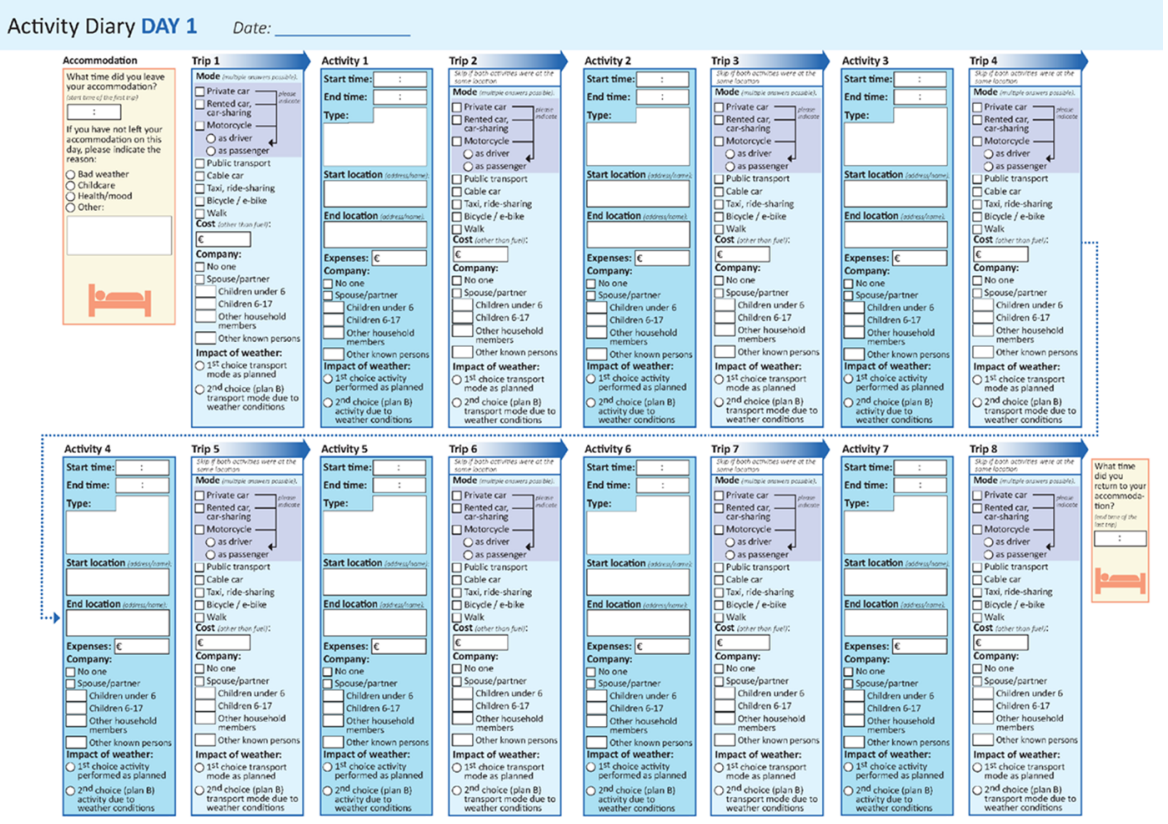

Fig. 19 PAPI questionnaire—page 2

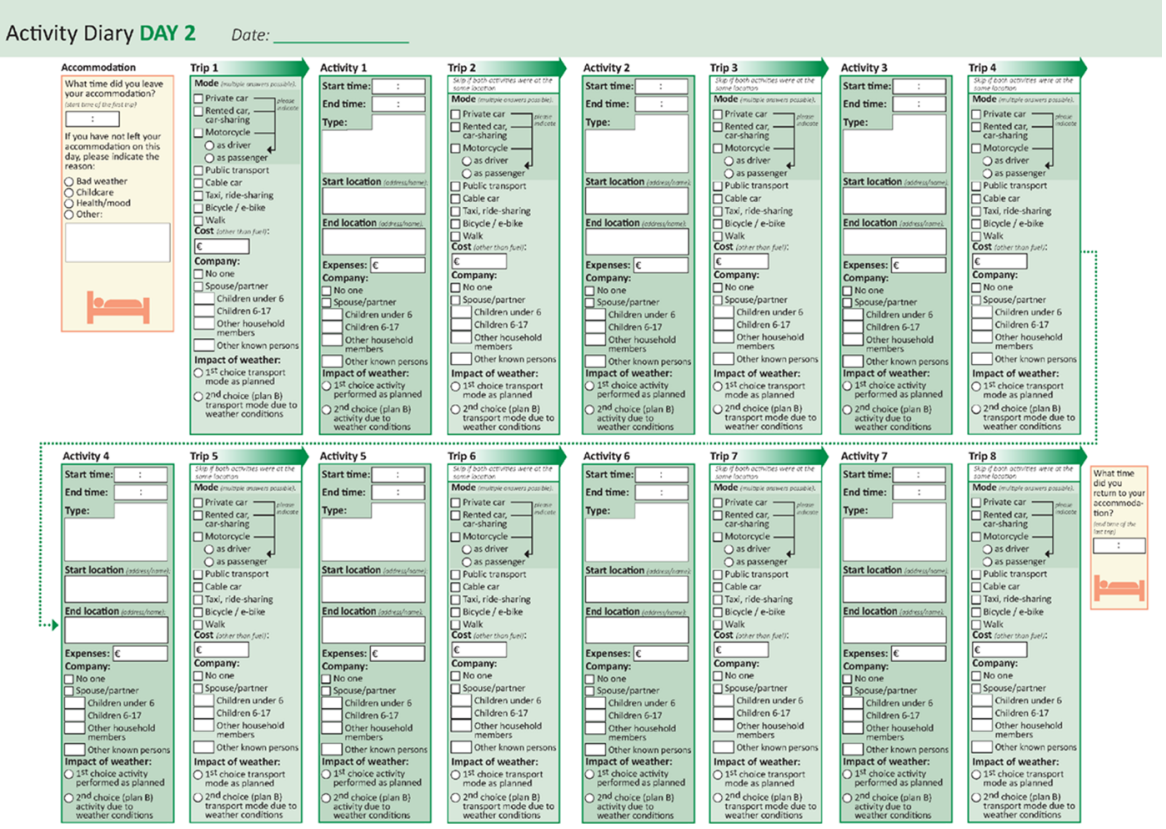

Fig. 20 PAPI questionnaire—page 3 
Acknowledgements The first author would like to thank the Faculty of Engineering Sciences at the University of Innsbruck for supporting him in the data collection process with need-based scholarships (No. 1092191, No. 1354749). We would also like to thank Emma Komarek, former student assistant in the Unit of Intelligent Transport Systems at the University of Innsbruck, for her work on data digitalization and data cleansing.

Author's contributions BB: Conceptualization, Methodology, Formal analysis, Investigation, WritingOriginal Draft, Visualization. MM: Conceptualization, Resources, Writing-Review \& Editing, Supervision. KWA: Conceptualization, Writing-Review \& Editing, Supervision.

Funding Open access funding provided by University of Innsbruck and Medical University of Innsbruck.

Availability of data and material The survey data along with a codebook and metadata are currently being prepared for publication in a repository.

\section{Declarations}

Conflict of interest On behalf of all authors, the corresponding author declares no conflict of interest.

Open Access This article is licensed under a Creative Commons Attribution 4.0 International License, which permits use, sharing, adaptation, distribution and reproduction in any medium or format, as long as you give appropriate credit to the original author(s) and the source, provide a link to the Creative Commons licence, and indicate if changes were made. The images or other third party material in this article are included in the article's Creative Commons licence, unless indicated otherwise in a credit line to the material. If material is not included in the article's Creative Commons licence and your intended use is not permitted by statutory regulation or exceeds the permitted use, you will need to obtain permission directly from the copyright holder. To view a copy of this licence, visit http://creativecommons.org/licenses/by/4.0/.

\section{References}

Abteilung Raumordnung und Statistik, Land Tirol (2019) Landesstatistik Tirol. https://www.tirol.gv.at/stati stik-budget/statistik/.

Ahas, R., Aasa, A., Roose, A., Mark, Ü., Silm, S.: Evaluating passive mobile positioning data for tourism surveys: an Estonian case study. Tour. Manage. 29, 469-486 (2008)

Alivand, M., Hochmair, H., Srinivasan, S.: Analyzing how travelers choose scenic routes using route choice models. Comput. Environ. Urban Syst. 50, 41-52 (2015)

Andrey, J., Mills, B., Leahy, M., Suggett, J.: Weather as a chronic hazard for road transportation in Canadian cities. Nat. Hazards 28, 319-343 (2003)

Andridge, R.R., Little, R.J.A.: A review of hot deck imputation for survey non-response. Int. Stat. Rev. 78, 40-64 (2010)

Anta, J., Pérez-López, J.B., Martínez-Pardo, A., Novales, M., Orro, A.: Influence of the weather on mode choice in corridors with time-varying congestion: a mixed data study. Transportation 43, 337-355 (2016)

Arce, C.H., Pisarski, A. (2009) Surveys of Tourists and Transients: Synthesis of a Workshop, Transport survey methods: Keeping up with a changing world eds P. Bonnel, M. Lee-Gosselin, J.P. Zmud and J.-L. Madre, pp. 243-248. Bingley, UK: Emerald.

Armstrong, R.W., Mok, C.: Leisure travel destination choice criteria of Hong Kong residents. J. Travel Tour. Mark. 4, 99-104 (1995)

Aschauer, F., Rösel, I., Hössinger, R., Kreis, H.B., Gerike, R.: Time use, mobility and expenditure: an innovative survey design for understanding individuals' trade-off processes. Transportation 46, 307-339 (2018)

Austrian National Tourist Office (2014). T-MONA Urlauberbefragung. Vienna.

Axhausen, K.W.: Definition Of Movement and Activity For Transport Modelling. In: Hensher, D.A., Button, K. (eds.) Handbook of transport modelling, pp. 329-343. Elsevier, Amsterdam, London (2008)

Axhausen, K.W. (2015). Kommentar SN 640003 Verkehrserhebungen: Methoden der Verkehrsbefragungen Schlussbericht VSS 2009/103. Arbeitsberichte Verkehrs- und Raumplanung, 1064, IVT, ETH Zürich. 
Axhausen, K.W., Schmid, B. and Weis, C. (2015). Predicting response rates updated. Arbeitsberichte Verkehrs- und Raumplanung, 1063, IVT, ETH Zürich.

Axhausen, K.W., Schönfelder, S., PTV AG and Fell, B. (2000). Mobidrive questionnaires, ETH Zurich.

Barchiesi, D., Moat, H.S., Alis, C., Bishop, S., Preis, T.: Quantifying international travel flows using flickr. PloS one 10, e0128470 (2015)

Beard, J.G., Ragheb, M.G.: Measuring leisure motivation. J. Leis. Res. 15, 219-228 (1983)

Becken, S., Wilson, J.: The impacts of weather on tourist travel. Tour. Geogr. 15, 620-639 (2013)

Ben-Akiva, M., Bergman, M.J., Daly, A.J. and Ramaswamy, R. (1984) Modelling inter-urban route choice behaviour, In: Proceedings of the ninth international symposium on transportation and traffic theory eds R. Hamerslag and J. Volmuller, pp. 299-330. Utrecht: VNU Science Press.

Bhat, C.R., Astroza, S., Bhat, A.C.: On allowing a general form for unobserved heterogeneity in the multiple discrete-continuous probit model: formulation and application to tourism travel. Transp. Res. Part b: Methodol. 86, 223-249 (2016)

Bieger, T., Laesser, C.: Future Living Conditions and Mobility: Travel Behavior of Alpine Tourists. In: Weiermair, K., Mathies, C. (eds.) The tourism and leisure industry: shaping the future, pp. 253-270. Abingdon; Routledge, New York (2013)

Bieger, T., Laesser, C.: Information sources for travel decisions: toward a source process model. J. Travel Res. 42, 357-371 (2016)

Bieland, D., Sommer, C., Witte, C.: Uncommon leisure traffic - analyses of travel behaviour of visitors. Transp. Res. Proc. 25, 3971-3984 (2017)

Björk, P., Jansson, T. (2008). Travel Decision-making: The Role of Habit. MPRA Paper.

Böhler, S., Grischkat, S., Haustein, S., Hunecke, M.: Encouraging environmentally sustainable holiday travel. Transp. Res. Part a: Policy Pract. 40, 652-670 (2006)

Brög, W. (2009) The New KONTIV® Design. http://www.socialdata.de/info/KONTIV_engl.pdf. Accessed 30.08.2018.

Bundesamt für Statistik (BFS) (2017). Verkehrsverhalten der Bevölkerung: Ergebnisse des Mikrozensus Mobilität und Verkehr 2015. Statistik der Schweiz. Neuchâtel, CH.

Bundesministerium für Verkehr und digitale Infrastruktur (2018). Mobilität in Deutschland - MiD: Ergebnisbericht. Bonn.

Bundesministerium für Verkehr, Innovation und Technologie (2016). Österreich unterwegs 2013/2014: Ergebnisbericht zur österreichweiten Mobilitätserhebung.

Bursa, B. and Mailer, M. (2018) Car-less on holiday: sustainable tourist travel in Alpine Regions, Tourism naturally conference.

Cambridge Systematics Inc. (1996). Travel Survey Manual. United States.

Cavallaro, F., Ciari, F., Nocera, S., Prettenthaler, F., Scuttari, A.: The impacts of climate change on tourist mobility in mountain areas. J. Sustain. Tour. 25, 1063-1083 (2017)

Chen, C., Ma, J., Susilo, Y., Liu, Y., Wang, M.: The promises of big data and small data for travel behavior (aka human mobility) analysis. Transp. Res. Part c Emerg. Technol. 68, 285-299 (2016)

Christensen, L., Nielsen, O.A. (2018) What Do European Tourism Demand Surveys Tell About Long Distance Travel?,In: TRB 97 th annual meeting compendium of papers.

Chua, A., Servillo, L., Marcheggiani, E., Moere, A.V.: Mapping Cilento: using geotagged social media data to characterize tourist flows in southern Italy. Tour. Manage. 57, 295-310 (2016)

Crawford, D.W., Jackson, E.L., Godbey, G.: A hierarchical model of leisure constraints. Leis. Sci. 13, 309-320 (1991)

Crompton, J.: Structure of vacation destination choice sets. Ann. Tour. Res. 19, 420-434 (1992)

Crompton, J.L.: Motivations for pleasure vacation. Ann. Tour. Res. 6, 408-424 (1979)

Day, J., Chin, N., Sydnor, S., Cherkauer, K.: Weather, climate, and tourism performance: a quantitative analysis. Tour. Manag. Perspect. 5, 51-56 (2013)

De Knop, P.: Sport tourism in Belgium. Opinion paper. J. Sport Tour. 9, 291-292 (2007)

Decrop, A.: Vacation decision making. CABI, Wallingford (2006)

Decrop, A.: Destination choice sets: an inductive longitudinal approach. Ann. Tour. Res. 37, 93-115 (2010)

Denstadli, J.M., Jacobsen, J.K.S.: The long and winding roads: Perceived quality of scenic tourism routes. Tour. Manage. 32, 780-789 (2011)

Dickinson, J.E., Robbins, D.: Using the car in a fragile rural tourist destination: a social representations perspective. J. Transp. Geogr. 15, 116-126 (2007)

Dickinson, J.E., Robbins, D.: Representations of tourism transport problems in a rural destination. Tour. Manage. 29, 1110-1121 (2008)

Elsasser, H., Bürki, R.: Climate change as a threat to tourism in the Alps. Climate Res. 20, 253-257 (2002) 
Eymann, A., Ronning, G.: Microeconometric models of tourists' destination choice. Reg. Sci. Urban Econ. 27, 735-761 (1997)

Federal Highway Administration (2017) National Household Travel Survey. https://nhts.ornl.gov.

Fodness, D., Murray, B.: A model of tourist information search behavior. J. Travel Res. 37, 220-230 (1999)

Frank, L., Bradley, M., Kavage, S., Chapman, J., Lawton, T.K.: Urban form, travel time, and cost relationships with tour complexity and mode choice. Transportation 35, 37-54 (2007)

Gerike, R., Schulz, A.: Workshop synthesis: surveys on long-distance travel and other rare events. Transp. Res. Proc. 32, 535-541 (2018)

Gilbert, D., Abdullah, J.: Holidaytaking and the sense of well-being. Ann. Tour. Res. 31, 103-121 (2004)

Godbey, G., Crawford, D.W., Shen, X.S.: Assessing hierarchical leisure constraints theory after two decades. J. Leis. Res. 42, 111-134 (2010)

Golob, T.F., Recker, W.W.: Relationships among urban freeway accidents, traffic flow, weather, and lighting conditions. J. Transp. Eng. 129, 342-353 (2003)

Gössling, S., Hall, C.M. (2006). Tourism and global environmental change: ecological, social, economic and political interrelationships / edited by Stefan Gössling and C. Michael Hall. Contemporary geographies of leisure, tourism, and mobility. London, Taylor \& Francis Group / Books.

Gössling, S., Scott, D., Hall, C.M., Ceron, J.-P., Dubois, G.: Consumer behaviour and demand response of tourists to climate change. Ann. Tour. Res. 39, 36-58 (2012)

Gross, S., Grimm, B.: Sustainable mode of transport choices at the destination - public transport at German destinations. Tour. Rev. 73, 401-420 (2018)

Gühnemann, A., Kurzweil, A., Mailer, M.: Tourism mobility and climate change - a review of the situation in Austria. J. Outdoor Recr. Tour. 34, 100382 (2021)

Gursoy, D., McCleary, K.W.: An integrative model of tourists' information search behavior. Ann. Tour. Res. 31, 353-373 (2004)

Hardy, A., Aryal, J.: Using innovations to understand tourist mobility in national parks. J. Sustain. Tour. 28, 263-283 (2020)

Hardy, A., Hyslop, S., Booth, K., Robards, B., Aryal, J., Gretzel, U., Eccleston, R.: Tracking tourists' travel with smartphone-based GPS technology: a methodological discussion. Info. Technol. Tour. 17, 255274 (2017)

Heinen, E., van Wee, B., Maat, K.: Commuting by bicycle: an overview of the literature. Transp. Rev. 30, 59-96 (2010)

Hewer, M.J., Scott, D.J., Gough, W.A.: Differences in the importance of weather and weather-based decisions among campers in Ontario parks (Canada). Int. J. Biometeorol. 61, 1805-1818 (2017)

Hoogendoorn-Lanser, S., Schaap, N.T., OldeKalter, M.-J.: The Netherlands mobility panel: an innovative design approach for web-based longitudinal travel data collection. Transp. Res. Proc. 11, 311-329 (2015)

Hranac, R., Sterzin, E.D., Krechmer, D., Rakha, H., Farzaneh, M.: Empirical Studies on Traffic Flow in Inclement Weather, Technical report. The Federal Highway Administration (FHWA), U.S. Department of Transportation, publication number FHWA-HOP-07-073 (2006). https://rosap.ntl.bts.gov/ view/dot/42251

Iso-Ahola, S.E. (1984) Social psychological foundations of leisure and resultant implications for leisure counseling, Leisure counseling: concepts and applications ed E.T. Dowd, pp. 97-125. Springfield, IL: C.C. Thomas.

Jacobsen, J.K.S.: Segmenting the use of a scenic highway. Tour. Rev. 51, 32-38 (1996)

Janzen, M., Vanhoof, M., Smoreda, Z., Axhausen, K.W.: Closer to the total? Long-distance travel of French mobile phone users. Travel Behav. Soc. 11, 31-42 (2018)

Juschten, M., Hössinger, R.: Out of the city - but how and where? A mode-destination choice model for urban-rural tourism trips in Austria. Curr. Issue Tour. 24, 1465-1481 (2021)

Klassen, N. (2001). Einfluss der Information auf die individuelle Freizeitmobilität: Anwendung der Stated Preference Methode auf die Potentialabschätzungen eines Freizeit- und Naherholungsinformationssystems. Ph. D. Thesis,Technische Universität München. München.

Koenig, U., Abegg, B.: Impacts of climate change on winter tourism in the swiss alps. J. Sustain. Tour. 5, 46-58 (1997)

Koetse, M.J., Rietveld, P.: The impact of climate change and weather on transport: an overview of empirical findings. Transp. Res. Part d: Transp. Environ. 14, 205-221 (2009)

Köll, H. and Bader, M. (2011). Auswertung Mobilitätserhebung Tirol 2011. Reith bei Seefeld.

Kozak, M.: Comparative analysis of tourist motivations by nationality and destinations. Tour. Manage. 23, 221-232 (2002)

LaMondia, J., Bhat, C.R.: A study of visitors' leisure travel behavior in the northwest territories of Canada. Transp. Lett. 3, 1-19 (2013) 
LaMondia, J., Snell, T., Bhat, C.R.: Traveler behavior and values analysis in the context of vacation destination and travel mode choices. Transp. Res. Record: J. Transp. Res. Board 2156, 140-149 (2010)

Lanzendorf, M.: Mobility styles and travel behavior: application of a lifestyle approach to leisure travel. Transp. Res. Record: J. Transp. Res. Board 1807, 163-173 (2002)

Larsen, J., Urry, J., Axhausen, K.W.: Mobilities, networks, geographies. Ashgate (2006)

Lau, G., McKercher, B.: Understanding tourist movement patterns in a destination: a GIS approach. Tour. Hosp. Res. 7, 39-49 (2006)

Lavrakas, P.J.: Encyclopedia of Survey Research Methods. Thousand Oaks, California: SAGE Publications, book, ISBN 1849725489 (2008). http://www.worldcat.org/oclc/233969508

Lehto, X.Y., O’Leary, J.T., Morrison, A.M.: The effect of prior experience on vacation behavior. Ann. Tour. Res. 31, 801-818 (2004)

Leiner, D.J. (2020). SoSci Survey.

Le-Klähn, D.-T., Hall, C.M.: Tourist use of public transport at destinations - a review. Curr. Issue Tour. 18, 785-803 (2013)

Lew, A., McKercher, B.: Modeling tourist movements: a local destination analysis. Ann. Tour. Res. 33, 403-423 (2006)

Li, Y., Yang, L., Shen, H., Wu, Z.: Modeling intra-destination travel behavior of tourists through spatiotemporal analysis. J. Destin. Market. Manag. 11, 260-269 (2019)

Lin, Y., Kerstetter, D., Nawijn, J., Mitas, O.: Changes in emotions and their interactions with personality in a vacation context. Tour. Manage. 40, 416-424 (2014)

Liu, C., Susilo, Y.O., Karlström, A.: Investigating the impacts of weather variability on individual's daily activity-travel patterns: A comparison between commuters and non-commuters in Sweden. Transp. Res. Part a: Policy Pract. 82, 47-64 (2015)

Liu, C., Susilo, Y.O., Termida, A.N.: Subjective perception towards uncertainty on weather conditions and its impact on out-of-home leisure activity participation decisions (2016). http://urn.kb.se/resolve? urn=urn:nbn:se:kth:diva-187013

Lu, X., Pas, E.I.: Socio-demographics, activity participation and travel behavior. Transp. Res. Part a: Policy Pract. 33, 1-18 (1999)

Mailer, M., Abegg, B., Jänicke, L., Bursa, B.: Mobilitätsbedingte Klimawirkung einer alpinen Tourismusdestination. Zeitschrift Für Tourismuswissenschaft 11, 211-236 (2019)

Masiero, L., Zoltan, J.: Tourists intra-destination visits and transport mode: a bivariate probit model. Ann. Tour. Res. 43, 529-546 (2013)

Maze, T., Agarwai, M., Burchett, G.: Whether weather matters to traffic demand, traffic safety, and traffic operations and flow. Transp. Res. Record: J. Transp. Res. Board 1948, 170-176 (2006)

McKercher, B., Hardy, A., Aryal, J.: Using tracking technology to improve marketing: insights from a historic town in Tasmania, Australia. J. Travel Tour. Mark. 36, 823-834 (2019)

McKercher, B., Lau, G.: Methodological considerations when mapping tourist movements in a destination. Tour. Anal. 14, 443-455 (2009)

McKercher, B., Shoval, N., Park, E., Kahani, A.: The [Limited] impact of weather on tourist behavior in an urban destination. J. Travel Res. 54, 442-455 (2014)

McKercher, B., Zoltan, J.: Tourist flows and spatial behavior. In: Lew, A.A., Hall, C.M., Williams, A.M. (eds.) The Wiley Blackwell Companion To Tourism, pp. 33-44. John Wiley \& Sons, Oxford, UK (2014)

Mokhtarian, P.L. (2018) Why travel surveys matter in the Age of Big Data?, Transportation Research Circular E-C238, pp. 2-4. Washington DC, United States.

Mokhtarian, P.L., Salomon, I.: How derived is the demand for travel? Some conceptual and measurement considerations. Transp. Res. Part a: Policy Pract. 35, 695-719 (2001)

Mokhtarian, P.L., Salomon, I. and Redmond, L.S. (2001) Understanding the Demand for Travel: It's Not Purely 'Derived'. Innovation: the European journal of social science research, 14, 355-380.

Morley, C.: Technique and theory in tourism analysis. Tour. Econ. 18, 1273-1286 (2012)

NatCen Social Research (2019). National travel survey 2018: technical report. London.

Nawijn, J., Mitas, O., Lin, Y., Kerstetter, D.: How do we feel on vacation? A closer look at how emotions change over the course of a trip. J. Travel Res. 52, 265-274 (2013)

Newmark, G.: Conducting visitor travel surveys: a transit agency perspective. J. Public Transp. 17, 136-156 (2014)

Önder, I., Koerbitz, W., Hubmann-Haidvogel, A.: Tracing tourists by their digital footprints. J. Travel Res. 55, 566-573 (2016)

Orsi, F., Geneletti, D.: Using geotagged photographs and GIS analysis to estimate visitor flows in natural areas. J. Nat. Conserv. 21, 359-368 (2013) 
Pettebone, D., Newman, P., Lawson, S.R., Hunt, L., Monz, C., Zwiefka, J.: Estimating visitors' travel mode choices along the Bear Lake Road in Rocky Mountain National Park. J. Transp. Geogr. 19, 1210$1221(2011)$

Prato, C.G., Bekhor, S., Pronello, C.: Latent variables and route choice behavior. Transportation 39, 299319 (2012)

Prelipcean, A.C., Susilo, Y.O., Gidófalvi, G.: Collecting travel diaries: Current state of the art, best practices, and future research directions. Transp. Res. Proc. 32, 155-166 (2018)

Pröbstl-Haider, U., Haider, W., Wirth, V., Beardmore, B.: Will climate change increase the attractiveness of summer destinations in the European Alps? A survey of German tourists. J. Outdoor Recreat. Tour. 11, 44-57 (2015)

Provenzano, D., Hawelka, B., Baggio, R.: The mobility network of European tourists: a longitudinal study and a comparison with geo-located Twitter data. Tour. Rev. 73, 28-43 (2018)

Rüger, B. and Mailer, M. (2020) Autofreie Anreise in Urlaubsregionen: Maßnahmen zur Stärkung der Bahn. ETR - Eisenbahntechnische Rundschau, 7+8, 18-23.

Rugg, D.: The choice of journey destination: a theoretical and empirical analysis. Rev. Econ. Stat. 55, 64 (1973)

Ryan, C., Glendon, I.: Application of leisure motivation scale to tourism. Ann. Tour. Res. 25, 169-184 (1998)

Sabir, M.: Weather and Travel Behaviour. PhD Thesis. Amsterdam: Vrije Universiteit. https://research.vu.nl/ en/publications/weather-and-travel-behaviour OR https://core.ac.uk/download/pdf/15458608.pdf

Sammer, G., Fellendorf, M., Herry, M., Karmasin, H., Klementschitz, R., Kohla, B., Meschik, M., Rehrl, K. and Reite, T. (2011). KOMOD - KOnzeptstudie MObilitätsDaten Österreichs: Im Auftrag des Bundesministeriums für Verkehr, Innovation und Technologie, Programmlinie ways2go des Forschungsund Technologieprogramms iv2splus. Vienna.

Saneinejad, S., Roorda, M.J., Kennedy, C.: Modelling the impact of weather conditions on active transportation travel behaviour. Transp. Res. Part d: Transp. Environ. 17, 129-137 (2012)

Scarpa, R., Thiene, M.: Destination choice models for rock climbing in the northeast Alps: a latent-class approach based on intensity of participation. SSRN Electr. J. (2004). https://doi.org/10.2139/ssrn. 615641

Scarpa, R., Thiene, M., Train, K.: Utility in willingness to pay space: a tool to address confounding random scale effects in destination choice to the Alps. Am. J. Agr. Econ. 90, 994-1010 (2008)

Schlemmer, P., Blank, C., Bursa, B., Mailer, M., Schnitzer, M.: Does health-oriented tourism contribute to sustainable mobility? Sustainability 11, 2633 (2019)

Scott, D., Gössling, S., de Freitas, C.R.: Preferred climates for tourism: case studies from Canada, New Zealand and Sweden. Climate Res. 45, 61-73 (2008)

Shoval, N., Ahas, R.: The use of tracking technologies in tourism research: the first decade. Tour. Geogr. 18, 587-606 (2016)

Shoval, N., Isaacson, M., Chhetri, P.: GPS. In: Lew, A.A., Hall, C.M., Williams, A.M. (eds.) Smartphones, and the Future of Tourism Research, The Wiley Blackwell Companion to Tourism, pp. 251-261. Wiley, Oxford, UK (2014)

Simma, A., Schlich, R. and Axhausen, K.W. (2002). Destination choice modelling of leisure trips: The case of Switzerland. (99th ed.). Arbeitsberichte Verkehrs- und Raumplanung. Zürich.

Simmons, E., Wilmot, A.: Incentive payments on social surveys: a literature review. Survey Methodol. Bull. 53, 1-11 (2004)

Singer, E., Ye, C.: The use and effects of incentives in surveys. Ann. Am. Acad. Pol. Soc. Sci. 645, 112-141 (2012)

Singleton, P.A.: Exploring the positive utility of travel and mode choice. In: Goulias, K.G., Davis, A.W. (eds.) Mapping the Travel Behavior Genome, pp. 259-277. Elsevier, Amsterdam, Netherlands (2020)

Sirakaya, E., McLellan, R.W., Uysal, M.: Modeling vacation destination decisions. J. Travel Tour. Mark. 5, 57-75 (1996)

Sirakaya-Turk, E., Uysal, M., Hammitt, W.E. and Vaske, J.J. (2017). Research methods for leisure, recreation and tourism. (2nd edition). CABI tourism texts. Wallingford, Oxforshire, UK, CABI.

Sirakaya-Turk, E., Woodside, A.G.: Building and testing theories of decision making by travellers. Tour. Manage. 26, 815-832 (2005)

Sirgy, M.J., Kruger, P.S., Lee, D.-J., Yu, G.B.: How does a travel trip affect tourists' life satisfaction? J. Travel Res. 50, 261-275 (2011)

Sobolevsky, S., Bojic, I., Belyi, A., Sitko, I., Hawelka, B., Arias, J.M. and Ratti, C. (2015) Scaling of city attractiveness for foreign visitors through big data of human economical and social media 
activity,In: 2015 IEEE International Congress on Big Data (BigData Congress): June 27, 2015 - July 2, 2015, New York, New York, USA ed B. Carminati, pp. 600-607. Piscataway, NJ: IEEE.

Statistics Austria (2020) STATcube: Statistical database of statistics Austria. http://www.statcube.at.

Steiger, R., Abegg, B., Jänicke, L.: Rain, rain, go away, come again another day weather. preferences of summer Tourists in mountain environments. Atmosphere 7, 63 (2016)

Stekhoven, D.J., Bühlmann, P.: MissForest-non-parametric missing value imputation for mixed-type data. Bioinformatics 28, 112-118 (2012)

Termida, A.N., Susilo, Y.O., Franklin, J.P.: Observing dynamic behavioural responses due to the extension of a tram line by using panel survey. Transp. Res. Part a: Policy Pract. 86, 78-95 (2016)

Terrier, C. (2009) Tourist flows and inflows: on measuring instruments and the geomathematics of flows, Transport Survey Methods: Keeping up with a Changing World eds P. Bonnel, M. Lee-Gosselin, J.P. Zmud and J.-L. Madre, pp. 219-241. Bingley, UK: Emerald.

Thimm, T., Seepold, R.: Past, present and future of tourist tracking. J. Tour. Futures 2, 43-55 (2016)

Thompson, K., Schofield, P.: An investigation of the relationship between public transport performance and destination satisfaction. J. Transp. Geogr. 15, 136-144 (2007)

Thornton, P.R., Williams, A.M., Shaw, G.: Revisiting time-space diaries: an exploratory case study of tourist behaviour in Cornwall, England. Environ. Plan. a: Econ. Space 29, 1847-1867 (1997)

Thrane, C.: Examining tourists' long-distance transportation mode choices using a Multinomial Logit regression model. Tour. Manag. Perspect. 15, 115-121 (2015)

Tooley, M.S.: Incentives and rates of return for travel surveys. Transp. Res. Record: J. Transp. Res. Board 1551, 67-73 (1996)

Tschopp, M., Beige, S. and Axhausen, K.W. (2010). Verkehrssysteme, Touristenverhalten und Raumstruktur in alpinen Landschaften. Forschungsbericht NFP 48, vdf Hochschulverlag AG.

Unger, R., Abegg, B., Mailer, M., Stampfl, P.: Energy consumption and greenhouse gas emissions resulting from tourism travel in an alpine setting. Mt. Res. Dev. 36, 475-483 (2016)

United Nations (2010). International Recommendations for Tourism Statistics. (Rev. 1). Studies in Methods. New York.

van Buuren, S. (2018). Flexible imputation of missing data. (Second edition). Chapman and Hall/CRC Interdisciplinary Statistics Series. Boca Raton, CRC Press Taylor \& Francis Group.

van Nostrand, C., Sivaraman, V., Pinjari, A.R.: Analysis of long-distance vacation travel demand in the United States: a multiple discrete-continuous choice framework. Transportation 40, 151-171 (2013)

Vu, H.Q., Li, G., Law, R., Zhang, Y.: Tourist activity analysis by leveraging mobile social media data. J. Travel Res. 57, 883-898 (2018)

Werbung, T.: Der Tiroler Tourismus. Zahlen, Daten und Fakten (2019). https://www.ttr.tirol/sites/default/ files/2020-09/Tiroler\%20Tourismus\%20-\%20Daten\%20und\%20Fakten\%202019_1.pdf

Woodside, A.G., Lysonski, S.: A general model of traveler destination choice. J. Travel Res. 27, 8-14 (1989)

Wu, C.-L., Carson, D.: Spatial and temporal tourist dispersal analysis in multiple destination travel. J. Travel Res. 46, 311-317 (2008)

Wu, L., Zhang, J., Fujiwara, A.: Representing tourists' heterogeneous choices of destination and travel party with an integrated latent class and nested logit model. Tour. Manage. 32, 1407-1413 (2011)

Yang, L., Wu, L., Liu, Y., Kang, C.: Quantifying tourist behavior patterns by travel motifs and geo-tagged photos from flickr. ISPRS Int. J. Geo Inf. 6, 345 (2017)

Zhao, X., Lu, X., Liu, Y., Lin, J., An, J.: Tourist movement patterns understanding from the perspective of travel party size using mobile tracking data: a case study of Xi'an, China. Tour. Manage. 69, 368-383 (2018)

Zoltan, J., McKercher, B.: Analysing intra-destination movements and activity participation of tourists through destination card consumption. Tour. Geogr. 17, 19-35 (2014)

Publisher's Note Springer Nature remains neutral with regard to jurisdictional claims in published maps and institutional affiliations.

Bartosz Bursa is a Senior Scientist at the Unit of Intelligent Transport Systems at the University of Innsbruck, where he obtained his PhD in 2020. Prior to that, Bartosz worked as a consultant and transportation expert in the UK, Germany and Poland. His research focus lies in particular in leisure-related travel behavior and modeling travel decisions of tourists and visitors, which despite being highly important in tourismdependent countries, are underrepresented in research. 
Markus Mailer is a Professor of transport planning at the University of Innsbruck, where he has been leading the Unit of Intelligent Transport Systems since 2010. He had previously worked for the BMW in Munich and at the Vienna University of Technology. In his research and teaching activities, he concentrates on sustainable transport, mobility services and traffic management considering people's needs as well as limited spatial and environmental conditions.

Kay W. Axhausen has been a Professor of transport planning at the Institute for Transport Planning and Systems at the ETH Zurich since 1999. He had previously held academic positions at the University of Oxford, Imperial College London and the University of Innsbruck. He has been involved in the measurement and modeling of travel behavior for the past 30 years, contributing in particular to the literature on stated choice methods, micro-simulation of travel behavior, valuation of travel time and its components, activity scheduling, and travel survey data collection. 